University of Rhode Island

DigitalCommons@URI

Open Access Dissertations

1991

\title{
The Role of Working Memory in Phoneme Awareness
}

Bernadette F. Evans

University of Rhode Island

Follow this and additional works at: https://digitalcommons.uri.edu/oa_diss

\section{Recommended Citation}

Evans, Bernadette F., "The Role of Working Memory in Phoneme Awareness" (1991). Open Access Dissertations. Paper 957.

https://digitalcommons.uri.edu/oa_diss/957

This Dissertation is brought to you for free and open access by DigitalCommons@URI. It has been accepted for inclusion in Open Access Dissertations by an authorized administrator of DigitalCommons@URI. For more information, please contact digitalcommons-group@uri.edu. 


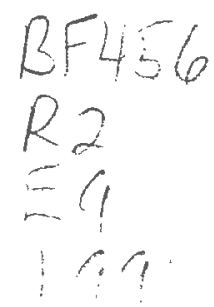

THE ROLE OF WORKING MEMORY IN

PHONEME AWARENESS

BY

BERNADETTE F. EVANS

A DISSERTATION SUBMITTED IN PARTIAL FULFILLMENT OF THE

REQUIREMENTS FOR THE DEGREE OF

DOCTOR OF PHILOSOPHY

IN

PSYCHOLOGY

\author{
UNIVERSITY OF RHODE ISLAND \\ 1991 \\ $2682(-6)$
}




\section{ABSTRACT}

The primary goals of this study were to examine the association between working memory and phoneme awareness, and to explore the relationships of these phonological processes with decoding and comprehension components of reading ability. Previously, only a few studies had examined the role of working memory in phoneme awareness, and the findings were inconclusive. A further goal of the present study was to examine whether simple phoneme awareness tasks (reguiring counting or segmenting of phonemes) relate differently to reading skills than do compound phoneme awareness tasks (requiring deletion or manipulation of phonemes).

Second-grade children whose reading skills were normally distributed served as subjects $(n=140)$. In addition to examining the abilities of the entire subject pool, two subgroups of skilled and lessskilled decoders were compared to determine if children having difficulty learning to read perform differently on phoneme awareness and working memory tasks. The subjects were given three working memory measures, three simple phoneme awareness tasks, and three compound phoneme awareness measures.

The results suggested that working memory ability is not strongly linked to performance on phoneme awareness tasks. Thus, these constructs represent relatively independent phonological processes. Second, the simple phoneme awareness tasks were found to factor separately from the compound phoneme awareness measures, auggesting it is important to distinguish between these two levels of metaphonological awareness.

For the entire pool of subjects, the working memory, Bimple phoneme awareness, compound phoneme awareness, and IQ measures were differentially related to decoding and comprehension performance. Decoding, a more basic skill, related highly to expertise on compound phoneme awareness measures, with simple phoneme awareness making a amaller contribution. Similarly, the subgroups of skilled and less- 
skilled decoders were significantly differentiated by their performance on both simple and compound phoneme awareness measures, but not on working memory. Comprehension performance, in contrast, was best predicted by compound phoneme awareness, verbal and nonverbal IQ, and working memory. The value of phoneme awareness measures for prediction and assessment purposes was discussed, as was the issue of how to control for IQ when examining phonological processes related to learning to read. 


\section{ACKNOWLEDGEMENTS}

I am especially grateful to Dr. Susan Brady, my major professor, for being supportive during this latter phase of my education, and for sharing her time, ideas, and expertise to benefit my professional development. I am also very grateful to Dr. Joseph Rossi for sharing his statistical knowledge and creative insights. Lastly, I thank Dr. Allan Berman, Dr. Janet Kulberg, and Dr. Susan Trostle for their highly regarded input and the contribution of their time.

I also extend a special thanks to the many school personnel, parents, and children who volunteered their Bervices and assisted me in this project. Gratitude is extended to: Sr. Ann Marie (principal), Mr. Barrios, Ms. Hedden, and to a very good friend, Mrs. Jenny Abate of st. Philomena's school; Ms. Cathy Harnett (principal), Ms. Busabos, Ms. Kittner, and Ms. Pitou of Warren schools; and Mr. Hayes (principal), Ms. Christensen, Ms. Eisenhaure, Mr. Garzilli, and Ms. Smith of Narragansett school.

I am also especially grateful to Heather MacLeod and Jennifer Thuber who gave generously of their time in assisting me in testing children, score protocols, conduct literature searches, and to complete work on the computer. Their assistance was invaluable to me.

Lastly, and most importantly, I want to thank my very special husband and group of U.R.I. friends who have been an inspiration to me and whose encouragement I have always appreciated. And, thanks be to God! 


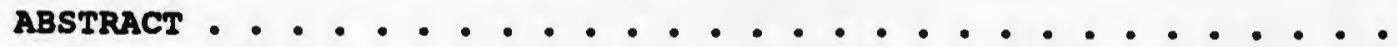

ACKNOWLEDGEMENTS ......................... IV

IIST OF TABLES ......................... v1

IIST OF FIGURES . . . . . . . . . . . . . . . . . . . . vili

CHAPTER

I. INTRODUCTION . . . . . . . . . . . . . . . 1

Background ..................... 1

Phonological Awareness ................. . 2

Morking Memory .................... . . 5

The Relation between Phonological

Awareness and Phonological

Coding in Working Memory ... . . . . . . . . . . 8

Hypotheses ................. 13

II. METHOD

Subjects ....................... 17

Measures ........................ 18

Selection Measures ................... 18

Experimental Measures.................. 20

Phoneme Awareness Measures .. . . . . . . . . . . . 20

Simple Phoneme Awareness ... . . . . . . . . . . . 20

Compound Phoneme Awareness .............. 22

Working Memory Tasks ..................... . 23

Additional Measure ................... . 25

Procedure ...................... . . 25

III. RESULTS

Correlations . . . . . . . . . . . . . . 27

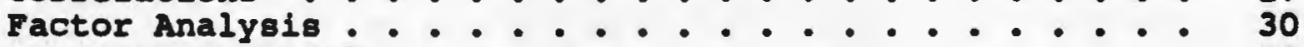

Measurement Model .................... . 32

Structural Models . . . . . . . . . . . . . . . 34

Step-wise Multiple Regression Analyses . . . . . . . . . 36

Relat Lonship Between Constructs . . . . . . . . . . 37

Relationship Between Manifest Variables . . . . . . . 46

Analysis-of-Covariance .............. 49

IV. DISCUSSION . . . . . . . . . . . . . . . 52

REFERENCES . . . . . . . . . . . . . . . . . . . . 59

APPENDICES

A. Segmentation Test . . . . . . . . . . . . . . 64

B. Segmentation Counting Test ................ 65

C. Phoneme Blending Test ................. . 66

D. Auditory Analysis Test . . . . . . . . . . . . . . . 67

E. Deletion Test ...................... 68

F. Pig Latin Test . . . . . . . . . . . . . . . 69

G. Single syllable Memory Test . . . . . . . . . . . . 70

H. Familiar Kord Span Memory Test . . . . . . . . . . . . . 71

I. Nonsense Word Span Memory Test . . . . . . . . . . . . 72

J. Reading Curriculum Survey . . . . . . ....... . 73

K. Correlation Coefficlents for All Observed Measures . . . . 76

I. Beta Values for Model Number 1 .............. 77

BIBLIOGRAPHY . . . . . . . . . . . . . . . . . . 78 
Table 1. Means, Standard Deviations, and Range of Composite IQ and Reading Achievement scores.

Table 2. Means and Standard Deviations of Memory, IQ, Reading, simple Phoneme Awareness, and Compound Phoneme Awareness Measures.

Table 3. Factor Loadings for each Factor's Predictor

Table 4. Intercorrelations between Factors.

Table 5. PBi Coefficients and Level of significance for

Latent Construct Pathways.

Table 6. Chi-squared Values, Goodness-of-Fit Indices, Root Mean Square Residuals, and Incremental Fit Indices for the Initial Three Structural Models.

Table 7. Results of step-wise Multiple Regression using IQ,

Working Memory, Simple Phoneme Awareness, and Compound Phoneme Awareness to Predict Overall Reading Performance.

Table 8. Results of step-wise Multiple Regression using IQ,

Working Memory, Simple Phoneme Awareness, and

Compound Phoneme Awareness as Predictors of Decoding

Performance.

Table 9. Results of Step-wise Multiple Regression using IQ, Working Memory, Simple Phoneme Awareness, and Compound Phoneme Awareness as Predictors of Passage Comprehension.

Table 10. Results of Step-wise Multiple Regression using Vocabulary as a Marker of IQ, and, Separately, Pattern Analysis as a Marker of IQ, and Working Memory, Simple Phoneme Awareness, and Compound Phoneme Awareness as Predictors of Overall Reading Performance.

Table 11. Results of Step-wise Multiple Regression using Vocabulary as a Marker IQ, and, Separately, Pattern Analysis as a Marker of IQ, and Working Memory. Simple Phoneme Awareness and Compund Phoneme Awareness as Predictors of Decoding Performance

Table 12. Results of Step-wise Multiple Regression using Vocabulary as a Marker IQ, and, Separately, Pattern Analysis as a Marker of IQ, and Working Memory, simple Phoneme Awareness and Compound Phoneme Awareness as Predictors of Comprehension Performance

Table 13. Results of step-wise Multiple Regression using IQ and Working Memory as Predictors of Compound Phoneme and Awareness, Separately, Simple Phoneme Awaarenes8.

Table 14. Results of Step-wise Multiple Regression with Word Attack as the Criterion, Verbal IQ Forced in First, and all Remaining Variables as predictors. 
Table 15. Results of Step-wise Multiple Regression with

Comprehension as the Criterion, Verbal IQ Forced

in First, and all Remaining Variables as Predictors.

Table 16. Means and Standard Deviations for Skilled and

Less-skilled Decoders on Three Phoneme Awareness Tasks and Three Working Memory Measures, and the Respective F-ratios with IQ as the Covariate. 
Figure 1. Model hypothesized to best fit data. 15

Figure 2. Alternative hypothesized model number $1 . \quad 16$

Figure 3. Alternative hypothesized model number $2 . \quad 16$

Figure 4. Measurement model with standardized solutions for 33 lambda and psi coefficients.

Figure 5. Beta weights of pathways between four predictor 39

Figure 6. Beta weights of pathways between four predictor 39 constructs with comprehension.

Figure 7. Beta weights of pathway between IQ and working memory with simple and compound phoneme awareness as separate criterion. 
CHAPTER I.

INTRODUCTION

The intent of this study is to examine the degree to which phoneme awareness relies on phonological codes in working memory. This investigation was conducted within the context of wagner's (1988) models that described the relationship of three phonological processes. Presently, the evidence is inconclusive about how working memory and phonological awareness relate to one another. It is proposed that working memory and phoneme awareness are independent processes, but that each latent ability makes a unique contribution to reading performance. This conclusion was based on the well-supported evidence that measures conjectured to rely on a phonological code are highly discriminating of good and poor readers (e.g., verbal working memory and phonological awareness). Also, it has been hypothesized that phoneme awareness tasks can be classified according to the degree of cognitive complexity the task involves (YOPp, 1988). Therefore, multiple measures reflective of these latent constructs, were administered in order to assess the factorial structure of these manifest variables and the relationship of their respective constructs.

In addition to exploring the relationship of the constructs to overall reading ability, the skill requirements for decoding versus passage comprehension are contrasted. Also, the profiles of lessskilled and skilled decoders are examined on subset of indicator variables.

\section{Background}

It is well-documented that children who efficiently process the phonological information in oral and written language tend to be better readers (e.g., in working memory and phonological awareness) (cf., Brady, 1988; Liberman, 1973; Lundberg, Frost, Peter8on, 1988; Stanovich, 1986; Torgesen, 1989; Vellutino \&canlon, 1987; Wagner, 1988). This finding has been consistently demonstrated across training, longitudinal and cross-sectional otudies (e.g., Bradley Bryant, 1978; 
Lundberg, et al., 1988, Mann \& Iberman, 1984; Stanovich, Cunningham, \& Cramer, 1984).

\section{Phonological Awareness}

Phonological awareness refers to a conscious awareness of the Bound structure of one's language. For example, given the word "dog," one would say it consists of three sounds or phonemes, or is one syllable, and rhymes with bog. Phonological awareness tasks generally require analyois or synthesis of word units. An "analyois" task, for instance, requires a child to segment a word into its respective speech units (phonemes or syllables). In contrast, a "synthesis" task requires a child to blend speech units to form a word.

It seems natural that the beginning reader who possesses a good understanding of the sound structure of words is apt to reveal better decoding skills than the child who experiences difficulty with phonological awareness tasks. This hypothesis has been substantially supported by prediction, reading-level matched, and training studies (Backman, 1983; Ball \& Blachman, 1988; Bradley \& Bryant, 1983; Fox \& Routh, 1980; 1983; Mann \& Liberman, 1984; Liberman, 1973; Lundberg, et al., 1988; Olson, Wise, Connors, Rack \& Fulker, 1989; Pratt \& Brady, 1988; Share, et al., 1984; Stanovich, Cunningham \& Cramer, 1984; Stanovich, Cunningham, Eeeman, 1984; Vellutino \& Scanlon, 1987).

With respect to prediction studies, Iiberman (1973) found that second graders' reading progress was significantly related to their performance on phonological awareness segmentation tasks in first grade. Stanovich, Cunningham, and Cramer (1984) administered a series of phonological awareness tasks to kindergarten nonreaders and later measured their reading performance in first grade. They found that the more cognitively complex tasks (i.e., tasks requiring a child to perform more than one cognitive operation) predicted first grade reading as well as a etandardized readiness test. In fact, two of their phonological awareness tasks accounted for 628 of the variance with respect to 
reading ability (e.g., word-to-word matching -- the subject hears two words and is asked, "Is the initial consonant different?"). similarly, Share, Jorm, Maclean, Matthews (1984) found that kindergarten children's performance on two phonological segmentation tasks significantly predicted reading achievement two years later. The children's earlier performance accounted for 398 of the later variance. Fox and Routh (1980) conducted a three year follow-up study on first graders. They found that the children who evidenced problems with segmentation tasks in first grade were severely reading disabled three years later. Other prediction studies have had similar findings (Calfee, Lindamood, \& Indamood, 1973; Vellutino \& scanlon, 1987). Prediction studies are not oufficient, however, to determine a causal relationship between phonological awareness and reading acquisition. In fact, some have argued that early reading experience may confound the observed relationship between phonological awareness and reading. In order to assess this latter hypothesis, Bradley and Bryant (1978) incorporated a reading-level match design. Bssentially, this design involves matching good and poor readers by reading achievement scores. Specifically, Bradley and Bryant (1978) matched six-year-olds with ten-year-olds who were reading at the same level. Thus, the ten-year-olda are likely to have had more reading and language experience than the $\mathrm{Bix}$-year-olds. The children were administered a sound categorization task (1.e., three of four words share a common sound and the child selects the word that does not belong). Bradey and Bryant (1978) found that the poor readers had significantly deficient segmentation skills relative to the six-year-olds. This finding provided support for a unidirectional relationship between phonological awareness and reading performance.

Iastly, training studies have offered further evidence to suggest phonological awareness skills are a necessary prerequisite to learning to read (Ball \& Blachman, 1988; Bradley \& Bryant, 1978; Fox \&outh, 1976; Lundberg, et al., 1988; Vellutino scanlon, 1987; Williams, 
1980). Lundberg, et al. (1988) trained preschoolers to attend to the phonological structure of language. Posttest measures in first and second grade indicated that children involved in the training program performed significantly better on phonological awareness tasks than the control group. Simultaneously, these children attained higher reading and spelling scores than their control counterparts. Thus, training in phonological awareness had a positive impact on reading and spelling acquisition.

To inveatigate the factorial structure of the phonological awareness measures, Lundberg et al. (1988) also conducted a factor analysis. Two latent variables were found. One variable represented phonological awareness measures that required subjects to analyze word units into syllables. The other variable represented tasks that required phonemic analysis/synthesis. The phoneme tasks were more effective at discriminating the experimental and control groups. Lundberg et al. (1988) concluded that the more cognitively demanding phonological awareness tasks (e.g., phoneme) were better measures for differentiating reading groups.

Another training program was instituted by Ball and Blachman (1988) whereby kindergarten children were assigned to three different treatment groups. Those children taught phoneme segmentation outperformed the other two groups on phoneme segmentation tasks and reading achlevement several months later. Ball and Blachman (1988) concluded that phoneme segmentation training should be included in all reading programs and that phoneme awareness appears to be a necessary prerequisite to early reading acquisition.

As noted, there is a sizeable body of literature that supports phonological awareness as a necessary akill for learning to read. In turn, such researchers encourage practitioners to incorporate phonological awareness measures as either a predictive index of future reading performance, allowing for early intervention, or in diagnosing potential reading disabilities. Also, these researchers recommend that 
phonological awareness training be included in preschool programs. since phonological awareness has received extensive attention empirically and in practice, this construct should continue to be examined in more depth. This issue will be addressed shortly.

\section{Morking Memory}

A second category of phonological processing pertains to the use of a phonological code in verbal working memory. Essentially, a reader engaged in decoding words must maintain the phonological code or soundbased representation of phonemes or syllables in working memory long enough to process whole words and, subsequently, phrases and sentences. Memory span tests are most commonly used to determine one's working memory capabilities (e.g., span of numbers, letters, words or nonsense Byllables).

A large percentage of working memory studies indicate that poor readers recall less information from working memory tasks than good readers (cf., Brady, 1988; Share, et al., 1984; Stanovich, 1982; Torgesen, 1978; Torgesen \& Houck, 1980; Wagner Torgesen, 1987). This performance deficit is especially evident with tasks dependent on verbal recoding (Cohen \& Netley, 1981; Katz, Shankweiler, Liberman, 1981; Rapala Brady (in presa); Shankweiler, Liberman, Mark, Fowler, * Fisher, 1979; Vellutino, 1987). Katz, et al. (1981), for instance, contrasted the recall of verbally codable versus noncodable items le.g., doodles). They found that only the verbally codable condition discriminated reading groups. This finding has been confirmed by others (cf., Rapala \& Brady (in press); Vellutino, Smith, Steger, \& Kaman, 1975), thus auggesting that poor readers do not experience a general memory impairment, but rather a specific deficit with respect to phonological codes. This type of memory deficit potentially impacts on auch reading skills as decoding (Dreyer, 1989; Wagner, Balthazor, Hurley, Norgan, Rashotte, Shaner, Simmons \& Stage, 1987) and use of contextual information (cf., Brady, 1988; Torgesen, 1982). In fact, 
memory measures typically account for 10 to 12 percent of the variance found in reading achievement tests (Brady, 1988).

Some researchers interested in the nature of the phonological code deficit with poor readers initially incorporated a phonological similarity effect or rhyme effect paradigm in their studies (Baddeley, 1966; Brady, Shankweiler, Mann, 1983; Mann Liberman, 1984; Shankweiler, Liberman, Mark, Fowler, Fisher, 1979). Lists of words are compiled such that they either rhyme or do not rhyme with each other. If a phonological code is being used in working memory, then rhyming words are apt to interfere with recall more so than nonrhyming words. In fact, good readers did evidence inferior recall with the rhyming word condition compared to the nonrhyme lists, and poor readers, in contrast, were less affected by the rhyme manipulation (Shankweiler, et al., 1979; Siegel \& Linder, 1984). They still recalled less than good readers, however, given either condition. Such results suggested that poor readers do use a phonological code but less efficiently than good readers.

Besides analyzing the effect of rhyme on recall performance, Brady et al. (1983) examined good and poor readers' errors when recalling rhyme and nonrhyme word lists. Also, in a second experiment, they manipulated the clarity with which words were heard on a speech perception task (1.e., words were presented in either a noise-masked or unmasked condition). This manipulation was designed to examine the effect of increased phonological demands on poor and good readers' skill in processing phonological information.

With respect to errors, poor readers made errors similar to those of good readers but more of them. specifically, poor readers committed more transposition errors (e.g., components of words are recombined) (see also Brady, Mann, Schmidt, 1987).

Aleo, as predicted, poor readers experienced more difficulty than good readers when perceiving words in noise. There was no substantial difference between reading groups when words were presented clearly. 
Both of the above findings supported the conclusion that poor readers use phonological codes but inefficiently, and most notably, when phonological demands are greater (cf., Rapala Brady, in press).

To further confirm the hypothesis that poor readers use phonological codes inefficiently in working memory, Rapala and Brady (in press) examined the relationship between a verbal short-term memory, and speech perception and production task. The demanding perception and production tasks were most effective in discriminating reading groups and aignificantly correlated with verbal short-term memory. Rapala and Brady concluded that poor readers were less efficlent at processing phonological information and, thus, memory span performance was impeded.

The studies cited above support the current theory regarding working memory -- operational efficiency theory --which suggests that poor readers are less efficient at using phonological codes (Baddeley, 1986). Baddeley's operational efficiency theory proposes that working memory is comprised of at least three limited capacity systems: an overriding executive control system; an articulatory 100p; and a visuospatial scratchpad. The less resources allocated to encoding information, the more resources available for storing information. A person who inefficiently processes phonological information in the articulatory loop, for example, has fewer resources reserved for storage. Baddeley's theory, with respect to reading performance, is supported by additional studies that have also examined speech perception and production (Snowling, 1981) and articulation rate (Baddeley, 1986; Blachman, 1983; Spring Capps, 1974; Torgesen Houck, 1980).

A recent study by Dreyer (1989) proposes an interesting paradigm that seems sultable for assessing efficiency in verbal working memory. Dreyer presented skilled and less skilled decoders with a nonsense eyllable; gave them an articulatory suppression task to prevent rehearsal; and then asked them to recall the oyllable over a five, ten or fifteen eecond interval. Dreyer (1989) found a atrong correlation 
between this single ayllable memory takk and decoding ability $(x=.65$, p<.01). The other memory tests she employed (e.g., digit and syllable epan) were only moderately correlated with decoding Bkill, thus, lese likely to discriminate skilled and less skilled decoders. Dreyer concluded that "the ability to [efficiently] retrieve phonemic representations from memory appeared to play a primary role in phonological decoding."

In conclusion, within the domain of reading acquibition and working memory performance, the operational efficiency theory has gained a range of empirical support. Poor readers apparently are less efficient in using phonological codes in working memory and, therefore, reveal inferior memory spans.

The Relation between Phonological Awareness and Phonological Coding in Working Memory

Phonological awareness and the use of phonological codes in working memory both seem to impact on reading performance. An interesting question to pursue is the degree to which these constructs relate to one another. To what extent do phonological awareness tasks rely on working memory? Many of the most discriminating phonological awareness tasks require subjects to hold a word in memory while simultaneously removing or manipulating its' phonemes or syllables, and aubsequently, verbalize the new word that incorporated the manipulation (e.g., deletion or Pig Latin task). By the nature of these tasks, it is apparent that they must rely to some degree on working memory. Also, do these two constructs represent two separate latent variables or one general ability? Answers to these questions are not only theoretically important but have practical implications as well. It is important to know whether these measures are redundant in order to determine their relative usefulness in screening batteries. Also, given a better understanding of what factors influence reading failure, proper methods for remediating reading problems can be determined. 
Few researchers have investigated the interrelationship of these two constructs. Wagner et al. (1987) proposed five models that could potentially describe the relationship among phonological processes. (The Wagner models included a third process -- phonological coding in lexical access.) of interest to this study, model number one suggests there is a unitary deficit common to all phonological processes; model number two proposes that all the processes are independent, and model number four describes phonological awareness and working memory as variables related to a common factor (1.e., phonological awareness requires one to use an efficient code in working memory).

The empirical evidence is presently inconclusive and contradictory with respect to which of pagner et al.'B (1987) models sufficiently explains this relationship. In this particular study, wagner and his colleagues administered five phonological awareness tasks, three working memory tests, and four lexical access measures to preschool nonreaders. They conducted a factor analysis and found two latent phonological processes existed. Working memory and phonological awareness tests loaded onto one factor, with lexical access loading onto the second factor. Thus, Wagner et al. (1987) concluded model number four best represented the relationship of working memory and phonological awareness. They further suggested that efficiency in working memory affects performance on phonological awareness tasks.

Others have supported this conclusion (Dreyer, 1989; Mann \& Liberman, 1984). Dreyer obtained a significant correlation between a syllable blending task and her single syllable memory test. Syllable blending did not, however, correlate with any of the other memory tests (e.g., syllable and digit span, and sentence imitation). This finding suggested that the single syllable Memory test may be a more sensitive measure than the other common memory tests. Mann and Liberman (1984) obtained a moderate correlation between a simple phonological awareness measure (syllable counting) and a memory span test for rhyming and nonrhyming word lists. 
In contrast to these findings, Mann (1984) conducted another study to assess the relationship between a phoneme reversal and word string memory task. Mann (1984) found these tasks were minimally correlated. Each variable accounted for a unique portion of the variance with respect to firat grade reading achievement.

similarly, share et al. (1984) found two phoneme segmentation tasks to account for 398 of the variance in predicting reading achievement in second grade. In contrast, a sentence memory test uniguely accounted for 3t of the variance. Neither was significantly related to the other.

Lastly, Wagner (1988) conducted a meta-analysis, examining longitudinal and training studies that incorporated phonological processing and reading achievement measures. A path analysis, with reading achievement as the criterion measure, revealed working memory and phonological awareness tasks to be relatively independent of each other, contradicting his earlier findings.

A number of methodological problems with the studies to date impede an interpretation of what the relationship is like between phonological awareness and working memory. For example, some of the studies have used only one phonological awareness or working memory test. Wultiple measures would be preferable to enhance the validity of the constructs assessed. A second problem is that sometimes an inadequate number of subjects for an insufficient number of measures have been used given the atatistics employed (e.g., factor analysis). Also, some studies based their conclusions on the results of several $t-$ test conducted on simple correlations (Dreyer, 1989; Wagner Torgesen, 1987). This method of analysis is prone to capitalize on error in order to obtain significant outcomes. Another element to consider is the impact of intelligence on subjects' performance. Some studies controlled for IQ while others did not.

The issue of IQ becomes especially important when one considers the relationship hypothesized to exist between it and working memory, 
and reading achievement. Gathercole, willis, and Baddeley (1990), for example, argue that a child's knowledge base or vocabulary influences his or her performance on a working memory task (also see Pennington, Orden, Kirson, Haith, 1990; Share, Jorm, Maclean, (Matthew8, 1984). Also, reading ability and vocabulary acquisition likely share a reciprocal relationship with one another. Therefore, differences noted between good and poor readers on memory measures may be influenced by general cognitive ability which is heavily weighted by verbal akill. ${ }^{1}$ Given the potential influence IQ can have on working memory and reading performance it would seem IQ should be controlled for more often in studies. Also, the removal of IQ would increase the validation of the working memory construct if the above is true. Some researchers, however, believe that controlling for IQ is too stringent (Gathercole, Willis, Baddeley, 1990). Removing its effect from analyses simultaneously excludes cognitive capabilities related to memory and reading ability. Others assert that IQ is an ill-defined concept and, therefore, should not be considered in reading research (stanovich, 1990). Overall, the inclusion of an IQ measure in this study would allow for further analysis of its relationship with the other constructs.

A further methodological shortcoming is that the memory measures used in studies have varied widely in task demands, possibly contributing to the inconsistent findings. Recall can be immediate or delayed; and the stimuli can be either one item or a string of items. In addition, tasks have differed in the atimuli utilized. Some contained words or pseudowords; others presented numbers or pictures for recall. The modality of presentation and mode of response also varied (e.g., aural or vibual presentation, and spoken or written response). similar problems exist with phonological awareness taskB le.g.,

Wonverbal ability is infrequently mentioned in the literature as it relates to reading in spite of some authors finding a significant relationship between it and reading achievement (Gathercole \& Baddeley, 1989). 
range of cognitive demands and modality of presentation). Some researchers, however, have investigated the relationship between various phonological awareness tasks (Backman, 1983; Fox \& Routh, 1976, Lundberg, at al., 1988; Stanovich, Cunningham \& Cramer, 1984; Vellutino \& Scanlon, 1987; Yopp, 1988). As mentioned before, Lundberg et al. (1984) performed a factor analysis in an attempt to examine the underlying factors with the phonological awareness tasks. They found two factors: syllable and phoneme. The phoneme segmentation tasks were viewed as more cognitively demanding than the syllable ones and were more predictive of later reading achievement.

similarly, Yopp (1988) examined ten phonological awareness tasks by conducting a factor analysis. She discovered two factors that apparently represented degree of task complexity: eimple versus compound tasks. The "simple" phonological awareness tasks reguired a child to perform only one cognitive operation (e.g., phoneme segmentation). The "compound" tasks required more than one cognitive operation (e.g., phoneme deletion). Yopp reported that a compound task (phoneme deletion) was the most significant in predicting reading achievement. She also suggested that the compound tasks may rely more on working memory than the simple tests.

In sum, while both phonological awareness and working memory have been found to be bignificantly related to reading ability, the relation between these phonological processes remains unclear. Those phonological awareness measures that are most strongly associated with reading performance also stress memory by requiring the stimuli to be stored and manipulated. Attempts to assess the link between phonological awareness and memory processes have suffered from a number of methodological shortcomings. Yet it remains important, both as a theoretical and practical matter, to explore the relationship between phonological awareness and working memory.

A final issue to consider is how these processes relate to different elements of reading such as decoding and passage 
comprehension. Some researchers have found working memory to be more strongly related to comprehension than decoding skill (Mann, Cowin, \& Schoenheimer, 1989; Turner \& Engle, 1989; Share, et al. 1984). Others claim phonological awareness affects comprehension indirectly. In consideration of the above, it seems an analysis of how phonological processes differentially affect decoding versus comprehension is necessitated. Such an analysis would enhance our understanding of these reading processes.

\section{Hypotheses}

The intent of this study is to explore the role of working memory in various phonological awareness tasks. Secondly, the relationship between these two processes, general cognitive ability, and elements of the reading process are explored.

To examine the construct validity of both phonological awareness and working memory, each is assessed by a number of measures. For phonological or phoneme awareness, the tasks are categorized as either simple or compound. This distinction is based on the theoretical grounds that compound tasks are apt to rely more on working memory than simple tasks. Both real words and pseudowords are used as stimuli. similarly, the working memory measures vary in task demands and require recall of words and pseudowords. This battery of tests permitted an evaluation of the latent factors that potentially underlie them as well as provide information regarding the relationship between phonological awareness and working memory.

The second purpose of this study is to evaluate how performance on phonological awareness and working memory tests related to reading achievement in second grade, and to assess the degree to which IQ influenced the other constructs. Therefore, it was hypothesized that given the various measures utilized, five latent variables surface: working memory, eimple phoneme awareness, compound phoneme awareness, reading achievement, and general intelligence. Emanating from this 
general hypothesis, several predictions were determined:

(1) Phoneme awareness tasks will distribute themselves according to the degree of complexity involved in the specific task (e.g., simple or compound).

(2) All working memory tasks will load onto the working memory latent variable, with Dreyer's single syllable Memory Test accounting for most of the variance.

(3) All three reading measures will load onto the reading achievement latent variables with word identification accounting for the larger portion of the variance.

(4) The two subtests intended to reflect general intelifigence will primarily load onto the IQ construct with vocabulary more strongly related to IQ.

(5) A reciprocal relationship will exist between IQ and working memory.

(6) A unidirectional relationship will be present between working memory with the simple and compound phoneme constructs and, subsequently, reading achievement. similarly, this directional pattern applied to the IQ construct.

(7) The latent variable for working memory will account for a large portion of the variance in the compound phoneme awareness variable and a moderate to small portion of the variance in the simple variable.

(8) Simple and compound phoneme awareness and working memory constructs will affect reading achievement independently of one another, with compound phoneme awareness accounting for more of the variance in reading achievement than the other two constructs.

The model hypothesized to fit the given data is suggested by the above predictions and represented in Figure 1. Two alternative models are proposed in Figures 2 and 3 . The alternative models differ from the primary in that phoneme awareness tasks are considered as one construct that cannot be classified according to complexity. The only difference between models two and three is that in model 2 working memory and 
phoneme awareness are independent while in model 3 a bidirectional relationship is considered.

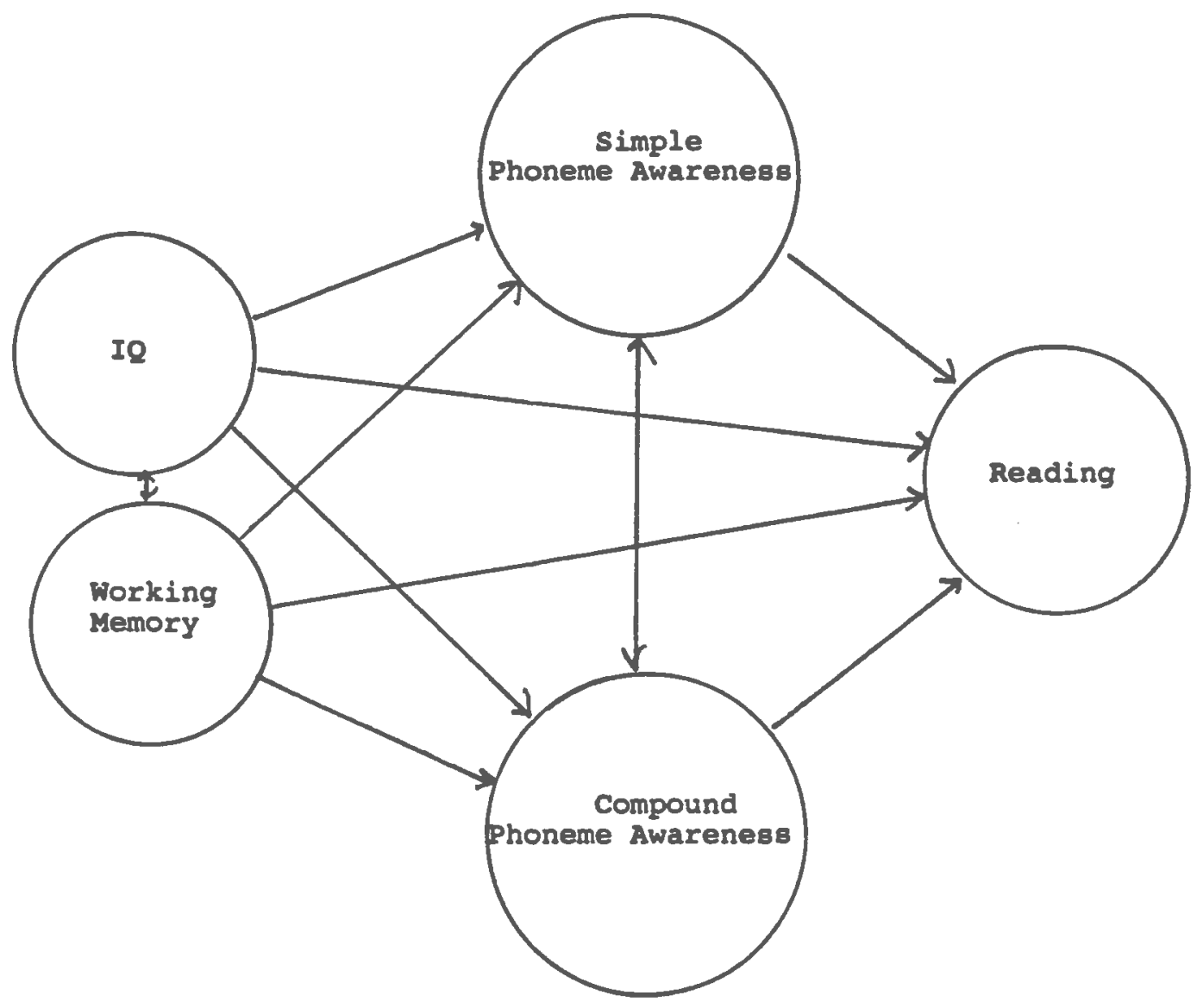

Figure 1. Model hypothesized to best fit data. 


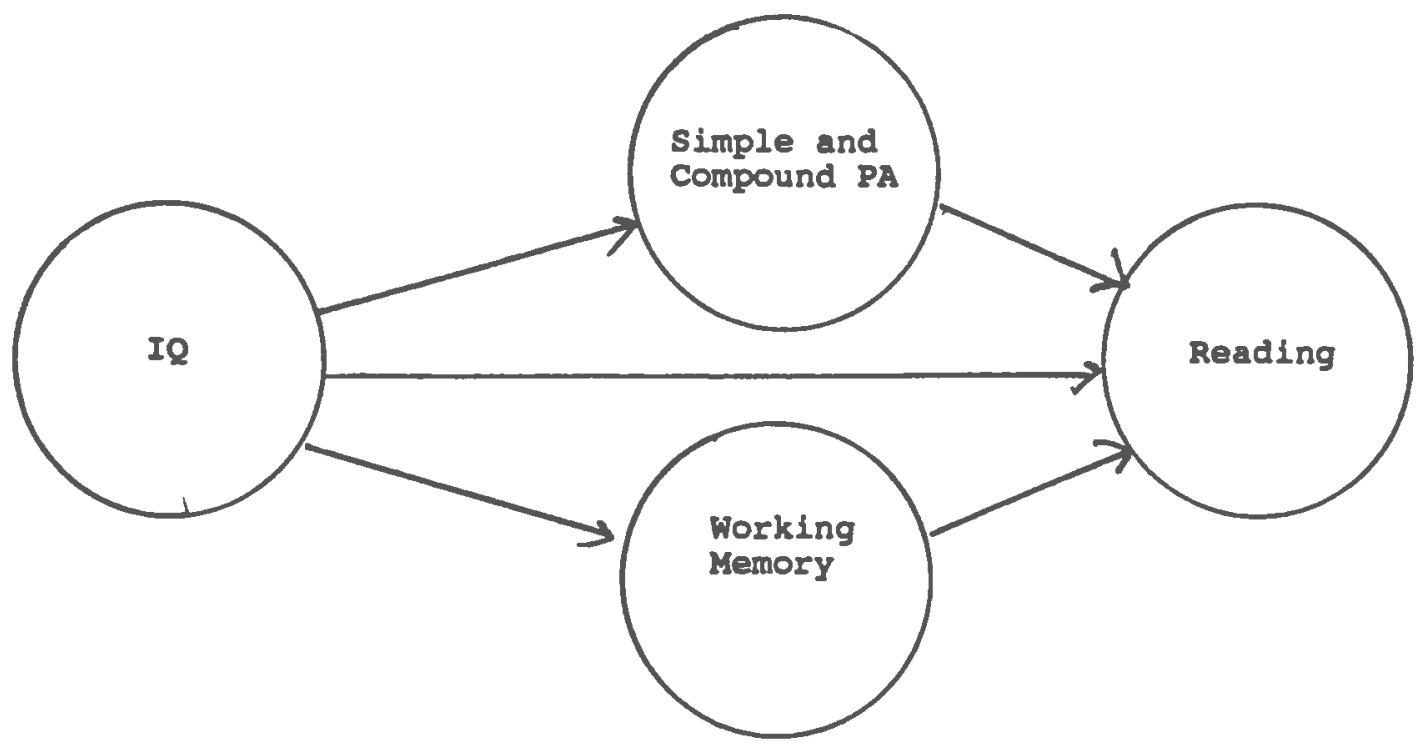

Figure 2. Alternative model number one.

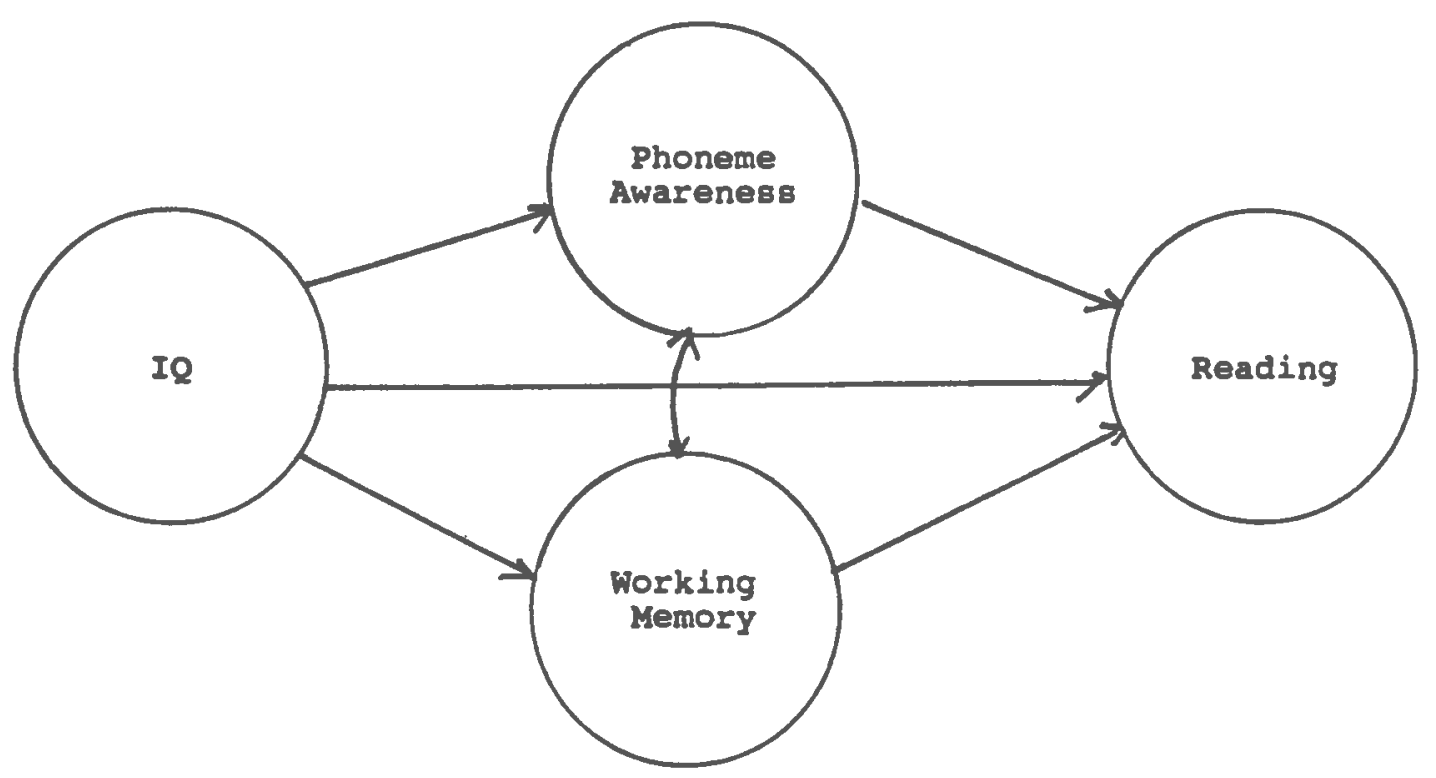

Figure 3. Alternative model number two. 


\section{CHAPTER II}

\section{METHOD}

\section{Subjects}

One hundred and forty second grade children from three suburban school systems in Rhode Island were selected to participate in the atudy. Children were included if they met the following criteria:

I0. Iligible subjects had to have composite standard age scores (SAS) that were in the range of 80 to 120 , a measured on the stanfordBinet Intelligence scale: Fourth Edition, Vocabulary and Pattern Analysis subtests (Thorndike, Hagen, sattler, 1986). This estimate assured the inclusion of children functioning from slightly below average to above average in intellectual ability (z-8core of 1.25 from the mean).

Word Attack. Reading achievement standard scores on the Word Attack subtest of the Woodcock-Johnson Reading Mastery Test/Revised, Form G, had to be between 76-123 (grade equivalent: 1.2 to 6.7). This range was chosen in order to include a distribution of poor to superior decoders (1.e., 6th to 94th percentile, reflecting a z-score of 1.5 from the mean).

Hearing. Since many of the tasks used in this study were auraldependent, no children with hearing impairments were included. An audiometer was used to screen for hearing deficits. Each potential subject's right and left ears were tested with tones at five different frequencies: $50 \mathrm{~Hz}(25 \mathrm{~dB}), 1000 \mathrm{~Hz}(20 \mathrm{~dB}), 2000 \mathrm{~Hz}(20 \mathrm{~dB}), 4000 \mathrm{~Hz}$ $(20 \mathrm{~dB})$, and $8000 \mathrm{~Hz}(20 \mathrm{~dB})$. Children who could not detect two or more of the ten tones were excluded from the study.

Additional criteria. Students participating in "English as a second language" classes were excluded. Also, students' records had to Indicate that they had no behavioral, emotional, or attentional problems, nor any physical handicaps.

One hundred eighty children were screened in order to obtain the sample of 140 subjects. Of those chlldren Included in the study, there 
were 58 females and $82 \mathrm{males}$. Descriptive statistics of the composite IQ scores, word attack scores, and ages are provided in Table 1.

Table 1.

Means, Standard Deviations, and Range of Composite Io and Reading Achievement Scores

\begin{tabular}{|c|c|c|c|}
\hline & Composite Io & hord Attack & Age \\
\hline $\mathbf{M}$ & 105 & 100 & 7 yгв. 9 mов. \\
\hline SD & 9 & 10 & 4 mos. \\
\hline Range & $80-120$ & $76-123$ & 7 угв.-9 угв. \\
\hline
\end{tabular}

\section{Measures}

The instruments used were the stanford-Binet Intelligence scale: Fourth Edition (Stanford-Binet) (Thorndike, Hagen, Sattler, 1986), the Woodcock Reading Mastery Test-Revised (WRMT-R) (Woodcock, 1987), Bix phoneme awareness measures, and three working memory tests.

\section{Selection Measures}

stanford-Binet. The Stanford-Binet was used to assess the children's cognitive ability and to ensure that their scores fell within the preset 80 to 120 composite sas range. The stanford-Binet is a widely used and accepted means of assessing general intelligence. Its construct validity was assessed with "non-exceptional" samples; the stanford-Binet composite score correlated .83 with the Wechsler Intelligence scale for Children-Revised and .89 with the mental processing composite of the Kaufman Aseessment Battery for Children. An abbreviated test battery of the stanford-Binet was used consisting of vocabulary and Pattern analysis subtestb. The manual provided information about the psychometric properties of these two subtests. This dyad correlated .88 and .91 for seven- and oight-year-olds, 
respectively, with full composite scores, indicating its validity as an IQ measure (Thorndike, Hagen, Sattler, 1986). A factor analysis revealed vocabulary to correlate .72 , and pattern analysis .69 , with the general intelligence factor. The intercorrelation between vocabulary and verbal reasoning was .90 and the correlation between pattern analysis and abstract/visual reasoning was .87 .

Internal reliability appeared to be adequate with alpha coefficients of .82 for vocabulary and .91 for pattern analysis for eight-year-olds. Test-retest measures after three months were .75 for vocabulary and .78 for pattern analysis subtests. Also, upon examination, both vocabulary and pattern analysis had an adequate sampling of items per level of task difficulty.

Woodcock Reading Mastery Test-Revised. The Woodcock Reading Mastery Test-Revised (WRMT-R) is a nationally-standardized, reliable and valid measure of reading achievement. The three subtests administered to the children were Passage Comprehension, Word Identification, and Word Attack subtests (split-half reliability coefficients for the end of second grade: $.95, .99$, and .97 , respectively). In the normative study, test-retest correlations after nine months in second grade were .97 (passage comprehension), .94 (word identification), and .90 (word attack). Also, each oubtest substantially correlated with the total reading score: .95 (passage comprehension), .98 (word ldentification), and .82 (word attack).

The manual provides limited information about the validity of these subtests. The content of each subtest, however, is adequate for evaluating a range of reading okills as indicated in the manual. Word Identification requires the child to name cominon words. The Word Attack subtest presents nonsense words and measures the child's decoding skills. Passage Comprehension requires a child to read a passage and orally fill in the blank with the most appropriate word. Each subtest provides a converted standard score. 


\section{Experimental Measures}

The various phonological awareness and working memory instruments are described below. It is important to note that there are few standardized measures available to assess phonological awareness and working memory, particularly in the manner necessitated by this study. Most of the measures that have been used in previous studies were designed with the intention of examining a specific research question and have not been standardized. For the tests used in the present study, reliability was assessed with either an alpha coefficient or Kuder-Richardson Formula 20. With respect to validity, these instruments are generally predictive of reading achievement and the content is consistent with their respective hypothetical constructs.

Bach category below (1.e., simple phoneme awareness, compound phoneme awareness, and working memory) contains three tests. Also, for both phoneme awareness and memory measures, there are two complementary tasks such that one consists of pseudowords and the other contains common or familiar words. The use of pseudoword tasks reduces the effect language experience or orthographic knowledge can have on these tests.

\section{Phoneme Awareness Measures}

Tasks were divided according to Yopp's simple and compound distinction (1988). Simple phoneme awareness measures require one cognitive operation while compound phoneme awareness tasks reguire a minimum of two cognitive operations for completion. Each task was designed to progress from easier to more difficult items.

\section{Simple phoneme awareness measures.}

1. Segmentation Task. (See Appendix A.) The Segmentation task used in this study was a modified version of the "Yopp-singer" (1988). In this task, subjects were asked to verbalize the individual phonemes heard in a real word. For example, given the test item "may," the child would say $" / \mathrm{m} /-/ a y / . "$ Twenty-seven words were presented for analysis. 
The modification of the Yopp-singer task allowed for an equal distribution of words containing particular syllabic patterns (e.g., consonant-vowel, vowel-consonant, consonant-vowel-consonant, etc.). Three items were included for each oyllabic pattern (consonant-vowel, vowel-consonant, vowel-consonant-consonant, consonant-consonant-vowel, consonant-consonant-vowel-consonant, consonant-vowel-consonantconsonant, consonant-consonant-vowel-consonant-consonant) except for the consonant-vowel-consonant pattern for which six items were used. All responses were recorded on tape to allow for accurate scoring and to assess interrater reliability. Yopp (1988) indicated this segmentation task's internal reliability to be .95 (Cronbach's alpha). Interrater reliability in this study was $r=.97$. The 27 phoneme items were scored as either correct or incorrect. Percentage correct scores were used in the analyses.

2. Counting Segmentation Task (pseudowords). (See Appendix B.) counting tasks were initially developed to assess a child's ability to count the number of phonemes heard in an utterance (e.g., Liberman, Shankweiler, Fischer, Carter, 1974). This test, likewise, required a child to count the number of sounds heard. For example, given the word "thoo" a child would indicate it had two sounds. The stimuli were 27 pseudowords designed to parallel the syllabic construction of the segmentation task (e.g., CV, VC, CVC, etc.) (see Appendix B). The child indicated the number of speech sounds by placing tiles on an index card in front of $\mathrm{him}$ or her. The responses were scored as either correct or incorrect. A percent correct score was used in the analyses. An alpha coefficient indicated the test's internal rellability to be $r=.80$.

3. Dreyer'B Blending Task (1989). (See Appendix C.) A modified version of Dreyer's (1989) phoneme blending test was used to assess each child's ability to recall a sequence of sounds and to blend them to form a meaningful word. The modification provided for a more even distribution of syllabic patterns which also made the test more sensitive by increasing the number of items to be analyzed. Eighteen 
words were presented with each phoneme in the word said, as much as possible, in isolation. The subject was asked to report the blended word. The items were presented in order of increasing number of phonemes in the target word. For example, given the sounds /k/ and /1/, a child would respond "key." Stimull were recorded by the experimenter onto audiotape and presented to the subjects through headphones to ensure consistency in presentation. The phonemes that composed the word were presented with a two second delay between phonemes. Items were scored as either correct or incorrect and the percent correct incorporated into the analyses. Dreyer (1989) reported an internal reliability coefficient of .63 for her version of the task.

\section{Compound phoneme awareness measures.}

1. Auditory Analysis Task (Rosner \& Simon, 1971) (AAT) (See Appendix D). This test, as designed by Rosner and simon (1971), required children to repeat a word spoken by the examiner without a particular sound (e.g., phoneme or syllable). For example, "say 'smile' without the $1 / 8 / \cdot . "$ The AAT, therefore, required a child to perform an additional mental manipulation relative to the tasks categorized as "simple phoneme awareness" tests. The AAT's criterion validity was established by correlating it with the stanford Achievement Test. It correlated .50 or better in grades two through five. Rosner and simon estimated the internal reliability to be .96 .

On the AAT, Rosner and Simon (1971) distributed their items according to which consonant or syllable was to be deleted. It began with simple syllable deletions from compound words and progressed to deleting phonemes from the beginning, middle, or end of a word. However, they did not include an equal number of items for each deletion position. In the present study, only the phoneme deletion stimuli were used, and the test was expanded to include twelve items that required a child to delete the initial consonant and six items each for which subjects were asked to omit the final and the medial consonants. Items were scored as either correct or incorrect and a percentage correct was 
ascertained for each protocol.

2. Deletion Task (Pseudoword Version of AAT). (See Appendix

B.) This task had the same requirements and conditions as the AAT, but consisted of pseudowords rather than real words. For example, for the one-syilable pseudoword "pim," subjects were asked to omit the /p/. The internal reliability in this study, as determined by an alpha coefficient, was $x=.84$.

3. Pig Latin Task (Pennington, Vanorden, Kirson, Haith, in press). (See Appendix F.) The Pig Latin task was derived from one used by Pennington and $\mathrm{his}$ colleagues. Subjects were given a word in which they were to remove the initial sound (either a phoneme or syllable) and to add it to the end of the word with the additional sound "ay." For example, "man" is converted to "anmay." In the present study, only the 12 phoneme 1tems were used. Nearly half of the words in the phoneme list began with monographic phonemes $(\mathrm{e} . g ., / d /)$, while the remaining Items began with digraphic phonemes (e.g., /sh/). Subjects responses were recorded on tape. Again, a percent correct score was determined. The Pig Latin's internal reliability for this study was $r=.88$. Interrater reliability was .96 .

Working memory tasks.

1. Dreyer's Single syllable Memory Test (1989). (See Appendix G.) The single syllable Memory Test required children to recall a nonsense syllable following either a five, ten or fifteen second interval. During the intervals, children were given an articulation suppression task to prevent rehearsal (1.e., reading a list of digits after hearing each stimulus). The memory test contained 20 items and 2 practice items which included five types of nonword syllables: vowel alone (V), VC, VC, CV, and CV, with four items representative of each category. (Vowels were either single ones or diphthongs.) There were six items for the five second interval and seven items for the ten and fifteen second intervals. The task was recorded by the experimenter. on the audiotape, each stimulus was followed by an electronic beep 
Bignaling the child to read a liat of random digits until a second beep was heard at either a 5, 10, or 15 second interval. At the second beep the child spoke the syllable previously heard into a microphone. A percentage correct score was determined for the overall total (i.e., number correct out of 20) and separately for /the 5, 10, and 15 second intervala. The test took approximately ten minutes to complete. Dreyer indicated the task's internal reliability to be .89 via a spearman-Brown calculation. The internal reliability for this sample, however, was .56.

2. Familiar Word Span Test (Brady, Shankweiler, \& Mann, 1983). (See Appendix H.) This word Span Test contained 10 lists of five onesyllable words. Brady, et al. (1983) used a list of fifty common nouns as their source for designing this test and controlled for word frequency, word length, and phonetic structure. The word strings were presented on audiotape at the approximate rate of one item per second. The children were asked to recall the words in each list in the order presented. Correct responses were scored: (1) in terms of the items recalled in the correct serial order, and, (2) for item recall only without consideration of serial order. For example, given the list "cat, fly, score, meat, scale" and a recall performance of "fly, cat, score, meat," a score of two correct for order, and four correct without consideration of order, would be given. Interrater reliability was .99. Internal reliability, as assessed with an alpha coefficlent, was . 82 .

3. Nonsense Word Span Test. (See Appendix I.) This test was designed to be similar to the Familiar Word Span Test. Each list, however, was composed of four monosyllablc pseudowords constructed to parallel the syllabic patterns in the familiar word memory task. (Trial runs of this test indicated that second graders had a difficult time retaining five pseudowords, requiring a reduction to four-word lista.) Each list was recorded on tape by the experimenter and presented over headphones to the subjects. Scoring procedures and administration were the same as the Familiar Word Span test. The interrater reliability was 
99. The alpha coefficient for ito internal reliability was .76. Additional Measure

Reading Curriculum Survey. (See Appendix J.) Teachers from the nine classrooms used in this study completed a reading curriculum survey. This survey informally assessed the comparability between instruction methods for the different classes and schools that participated in the study.

\section{Procedure}

After obtaining parental consent, each subject was tested individually on three separate occasions. Each session lasted fifteen to forty minutes and occurred within three to seven days of the other sessions. All participants in the study received a nonmonetary expression of appreciation at the conclusion of each session (i.e., otickers).

During the first session, the children were administered a hearing screening, the Stanford-Binet Vocabulary and Pattern Analysis subtests, and WRMT-R Word Attack, Word Identification, and Comprehension subtests, in that order. Each test was administered by the experimenter in the standardized manner recommended in the respective manuals.

Experimental measures were administered in the second and third sessions. The second session consisted of five tests and the third session contained the remaining four measures. To reduce potential order effects, three different test orders were used in sessions two and three. Each of the test orders was given to approximately one-third of the total number of subjects. Specifically, in the second session, one block of children was administered the Blending, Counting, Familiar Word Span, Pig Latin, and Yopp segmentation measures, in that order. In the third session, they completed the remainder of tests -- Nonsense Word Span, Deletion, single syllable Memory, and AAT tests -- in that sequence. The second block of children completed the Counting, Nonsense word span, Yopp, Single syllable Memory, and AAT tests in the second 
session. The third session consisted of the Deletion, Pig Iatin, Blending, and Famillar Word Span tasks. The third and last block of subjects received Familiar Hord Span, Counting, Blending, Yopp and PIg Latin first and then finished single syllable Memory, AAT, Nonsense Word span, and Deletion in their third and last session.

As noted above, the counting test always preceded the Yopp and Pig Latin tests. This ordering of tests was necessary in order to facilitate the children's comprehension of the Yopp and Pig Latin tests.

All experimental measures were administered in a prescribed, standard manner (see respective appendices). Two trained research assistants administered a majority of the tests to one-third of the subjects. The experimenter gave the remaining measures and tested the remaining two-thirds of the subjects. Each measure was aurally presented (either in person or on audlotape) and required an oral response. (The counting task was an exception in that children placed tiles on a card instead of responding orally.) As mentioned earlier, some responses were tape recorded to facilitate accurate scoring. At the completion of the testing phase, the two trained assistants rescored eighty percent of all protocols for the experimental measures. This process enabled us to obtain interrater reliability scores. 


\section{CHAPTER III}

RESULTS

Table 2 provides the mean and standard deviation for each of the fourteen measures utilized in this study. The single syllable Memory task provided an overall recall score and was further broken down into three units to examine differences in recall performance between five, ten, and fifteen second delays. A skewed distribution was noted with the single syllable Memory and Pig Latin tests, with a number of children obtaining zero or near zero scores.

Table 2.

Means and Standard Deviations of Memory, IQ, Reading, Simple Phoneme Awareness, and Compound Phoneme Awareness Measures

Measures Mean SD

\begin{tabular}{lrr} 
1. Nonsense Word Span & $40.78^{\mathrm{b}}$ & 13.98 \\
2. Familiar Word Span & $61.80^{\mathrm{b}}$ & 14.55 \\
3. Single Syllable Overall score & $35.41^{\mathrm{b}}$ & 14.23 \\
4. Single Syllable Five Seconds & $55.26^{\mathrm{b}}$ & 19.52 \\
5. Single Syllable Ten Seconds & $28.81^{\mathrm{b}}$ & 18.11 \\
6. Single Syllable Fifteen Seconds & $24.82^{\mathrm{b}}$ & 20.77 \\
7. S-B Vocabulary subtest & 107.36 & 12.22 \\
8. S-B Pattern Analysis & 101.89 & 9.51 \\
9. S-B Composite IQ & 105.19 & 9.21 \\
10. W-J Word Identification & 109.66 & 13.56 \\
11. W-J Word Attack & 100.93 & 10.60 \\
12. W-J Passage Comprehension & 105.60 & 10.22 \\
13. Counting Task (pseudowords) & $60.24^{\mathrm{b}}$ & 17.98 \\
14. Segmentation Task & $53.38^{\mathrm{b}}$ & 19.22 \\
15. Blending Task & 39.59 & 11.88 \\
16. Auditory Analysis Task & $63.22^{\mathrm{b}}$ & 20.37 \\
17. Deletion Task (pseudowords) & $51.16^{\mathrm{b}}$ & 20.12 \\
18. Pig Latin & $37.03^{\mathrm{b}}$ & 30.51 \\
\hline
\end{tabular}

bcores based on percentage correct

Before most analyses were conducted, it was necessary to determine which scoring procedure to use in the analyses with respect to Nonsense and Familiar Word spans. All protocols provided two recall scores. One method scored responses as correct if the words were recalled in correct order and the other scoring method did not consider order. The two 
measures yielded very similar results, though the percent correct was lower for the nonsense word task. Further, the correlation between the two scores was .85 for Familiar Word Span and .89 for Nonsense Word span. A reliability test was conducted and both scoring measures provided the same estimate of reliability -- alpha coefficient of .76. Therefore, since either scoring method appeared adequate, the score that did not consider order was incorporated into all further analyses unless otherwise stated.

A correlation matrix is provided in appendix $\mathrm{K}$ indicating the interrelationships and degree of significance between the observed variables. The Single syllable Memory measures were examined to assess which component would be used in further analyses. The 15 second measure was selected as the more sensitive of the other three, and revealed similar relationships with other variables as the memory test did. 2

\section{Correlations}

First, we looked at the measures indicative of the hypothetical constructs utilized in this study. Multiple measures of each construct were examined (1.e., aimple phoneme awareness, compound phoneme awareness, working memory, IQ and reading). Significant correlations between all pairs of measures tapping a given construct were obtained. In addition, the correlation matrix indicated that a strong relationship existed between the variables labeled as compound phoneme awareness measures (i.e., AAT, Deletion, and $\mathrm{Pig}$ Latin) and the reading measures (1.e., Word Identification, Word Attack, and Passage Comprehension) (e.g., r=.64 for AAT and word attack). Fairly strong correlations also existed between Vocabulary (i.e., Verbal $I Q)$ and the reading measures

${ }^{2}$ For those interested in using the single syllable Memory test it is important to realize that this task, at the 15 second interval, was highly frustrating for our sample of second graders. A semi-flat distribution was obtained which suggested that this sample may be too young for this test. It is also recommended that the number of test items per second delay conditions be equal. The present test included 7 items for the 10 and 15 second delay conditions but only 6 items for the 5 second delay. 
$(r=.40$ with comprehension and $r=.27$ with word attack), and Pattern Analysis (i.e., Nonverbal $I Q)$ with passage comprehension $(r=.34)$.

A strong relationship between compound phoneme awareness tasks and reading skill is well-documented in the literature, and is supported here. Also, vocabulary knowledge has been cited as a relevant factor in predicting a child's reading performance. In this case, vocabulary surfaced as being strongly related to comprehension, in particular, as was pattern analysis. A child's proficiency in decoding words, however, was less related to degree of vocabulary acquisition and unrelated to nonverbal, analytical skill.

Further review of the matrix reveals a moderate relationship between the designated compound phoneme awareness tasks with those labeled as simple phoneme tasks (i.e., Counting, segmentation, and Blending) (e.g., $r=.27$ between counting and AAT and $r=.36$ between Yopp and AAT). Also, a moderate relationship surfaced between vocabulary and working memory tasks (i.e., Familiar Word Span, Nonsense Word Span, and Single syllable Memory-Fifteen seconds) (e.g., $r=.38$ with Fws, and .23 with Nws).

By the nature of the phoneme awareness measures, one would expect them to share some common variance. Yet given the moderate correlation between the two, one would expect them to separate as constructs since each is apparently tapping something different. The moderate relationship between vocabulary and the working memory tasks is also of interest. Familiar Word span had a etronger correlation with vocabulary than did Nonsense Word Span, possibly reflecting shared lexical processing.

A eignificant correlation was found between ramiliar word span and Word Identification $(r=.23)$ and between Familiar Word Span and comprehension $(r=.31)$. The other two memory measures also had a significant relationship with comprehension. There was no apparent relationship, however, between working memory and compound phoneme awareness tasks (except between Nonsense Word Span and Deletion and 
Single Syllable Memory 15 seconds and Deletion). This finding suggests that performance on compound phoneme awareness tests are not determined by one's working memory capacity.

Lastly, simple phoneme awareness measures did not significantly correlate with comprehension but did with word attack. This result suggests that decoding relies on a basic awareness of the phonemic structure of words.

While some interesting associations were obtained, the simple correlations need to be interpreted cautiously since other variables have yet to be statistically controlled. For example, given the significant correlations between (1) working memory and vocabulary, (2) working memory and comprehension, and (3) vocabulary and comprehension, it will be important to consider the shared effects of IQ in the memory and comprehension association. Also, due to the likelihood of finding an inflated number of significant correlations through multiple t-tests, it is necessary to use more robust analyses that were less prone to capitalize on error.

\section{Factor Analysis}

The next step was to determine how these variables factored together and whether they loaded into the five constructs, as hypothesized. Therefore, a factor analysis (oblique rotation) was conducted followed by a series of structural models in which fifteen variables were incorporated: Nonsense Word Span, Familiar Word Span, Single Syllable Memory-15 seconds, Vocabulary, Pattern Analysis, Composite IQ, Counting, Segmentation, Blending, AAT, Deletion, Pig Latin, Word Identification, Word Attack, and Passage Comprehension. In order to confirm that the measures indeed represented separate constructs, a factor analyeis procedure was conducted (See Table 3 for results.) As predicted, measures corresponding to the constructs of $I Q$, working memory, and simple phoneme awareness factored out separately. The compound phoneme awareness and reading measures, however, factored together. The finding that compound phoneme awareness and reading 
measures loaded together supports the existence of a strong link between these two constructs and the skills reguired in the respective tasks. The results from the factor analysis also supported the hypothesis that a significant distinction exists between simple and compound phoneme awareness tasks. These four factors accounted for 678 of the variance among the variables. Table 4 provides the correlations between factors. Factor one pertains to the reading and compound phoneme awareness factor. Factor two refers to the IQ construct. The construct of working memory is represented by factor three. Lastly, factor four represents simple phoneme awareness.

Table 3.

Factor Loadings for Each Factor's Predictor Variables

\begin{tabular}{|c|c|c|c|c|}
\hline & Factor 1 & Factor 2 & Factor 3 & Factor 4 \\
\hline $\begin{array}{l}\text { WWS } \\
\text { FWS } \\
\text { Single Syllable Memory } \\
\text { Vocabulary } \\
\text { Pattern Analysis } \\
\text { Composite IQ } \\
\text { Count } \\
\text { Segmentation } \\
\text { Blending } \\
\text { AAT } \\
\text { Deletion } \\
\text { Plg Latin } \\
\text { Word Identification } \\
\text { Word Attack } \\
\text { Comprehension }\end{array}$ & $\begin{array}{r}.809 \\
.748 \\
.557 \\
.879 \\
.840 \\
.725\end{array}$ & $\begin{array}{l}.636 \\
.809 \\
.930\end{array}$ & $\begin{array}{l}.845 \\
.819 \\
.639\end{array}$ & $\begin{array}{l}.774 \\
.764 \\
.692\end{array}$ \\
\hline
\end{tabular}

Table 4.

Intercorrelations between Factors

\begin{tabular}{lccc}
\hline & IQ & Working Memory & SPA \\
\cline { 2 - 4 } & .34 & .26 & .26 \\
Reading/CPA & & .29 & $\begin{array}{r}.04 \\
.03\end{array}$ \\
IQ & & & \\
\hline
\end{tabular}


Measurement Model

since the factor analysis supported the existence of at least four factors, the data were examined in the form of a measurement model preceding the computation of structural models (using the Lisrel VI computer program). The measurement model examined the regression of each manifest variable to its respective construct or factor (lambda matrix, $\lambda$ ). The model also looked at the correlations between the latent components (Pai matrix, F). Figure 4 illustrates the relationships among the observed and latent variables for the five constructs: IQ, working memory, simple phoneme awareness, compound phoneme awareness, and reading. Table 5 summarizes the Psi's and their degree of significance.

Table 5 .

PB1 Coefficients and Level of Significance for Latent Construct Pathways

\begin{tabular}{|c|c|c|c|c|}
\hline & Working Kemory & SPA & CPA & Reading \\
\hline $\begin{array}{l}\text { IQ } \\
\text { Working Memory } \\
\text { SPA } \\
\text { CPA }\end{array}$ & $.613^{\star}$ & $\begin{array}{l}.113 \\
.118\end{array}$ & $\begin{array}{l}.506^{* \star} \\
.129 \\
.521^{* * *}\end{array}$ & $\begin{array}{l}.755^{* * *} \\
.224 \\
.255^{*} \\
.716^{* \star}\end{array}$ \\
\hline
\end{tabular}

With respect to the lambda parameters, verbal IQ (vocabulary) loaded most strongly with the IQ construct $(\lambda=.54)$. Familiar word span, similarly, was the most significant marker of working memory $(\lambda=$ 1.08)..$^{3}$ The segmentation task loaded most with simple phoneme awareness $(\lambda=.75)$, and AAT appeared to be the primary indicator of compound phoneme awareness $(\lambda=.91)$. Word Identification had the heaviest loading with reading $(\lambda=.97)$. These results, however, do not

${ }^{3}$ Lisrel VI does not necessarily correct for regression coefficients that exceed 1.0. A lambda slightly greater than 1.0 can be interpreted as an indicator that the variable is nearly equivalent to the construct. 
mean these teste are necessarily purer measures of the construct. On the contrary, for example, familiar word apan had a heavier verbal IQ component than nonsense word pan as noted in the discussion of the correlation matrix."

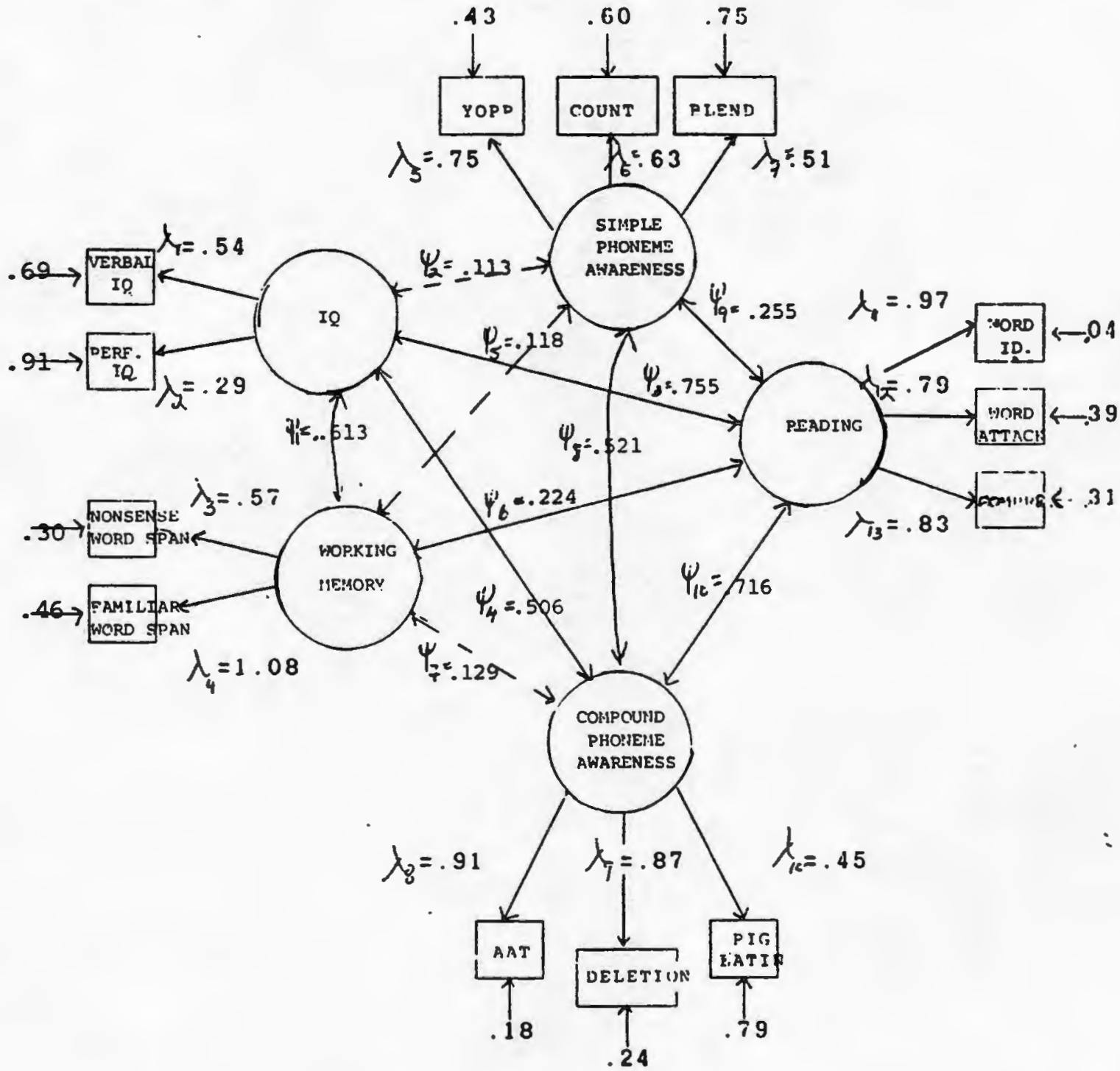

Fiqure 4. Measurement model with etandardised solutione for lambda and pai coefficients.

The single syllable Memory test was not used in computing the measurement or structural models. When the single syllable task was included, the program would not converge. Since the communality estimate for the single syllable task was the lowest for the working memory factor (.44 v8. .73) 1t was decided to run the models without 1 t. 
As the measurement model indicated, with the Psi parameters, IQ shared a significant relationship with working memory $(F=.613$, $p<$ $.05)$, compound phoneme awareness $(Y=.506, p<.001)$, and reading ( $P=$

.755, $\mathrm{p}<.001)$. Compound phoneme awareness was significantly correlated with simple phoneme awareness $(F=.521, p<.001)$ and reading $(F=.716, p<.001)$, and simple phoneme awareness indicated a significant correlation with reading $(F=.255, p<.05)$. (Relative to compound phoneme awareness, simple phoneme awareness tasks demonstrated a weaker relationship to reading.) Working memory correlated Bignificantly with reading $(Y=.224, p<.05)$. All other Psi pathways were nonsignificant le.g., working memory with compound phoneme awareness). Due to the mutual relationship IQ had with reading and working memory, a direct interpretation of the relationship between working memory and reading is not appropriate with such a model. The measurement model essentially provides a general understanding of how each construct independently relates to one another. In order to further assess the direct influence specific constructs had on one another, structural models were executed. Hierarchical stepwise multiple regressions were subsequently executed in which IQ was often forced in at the first step of the analyses. Specific relationships among the constructs were more accurately examined (e.g., working memory with reading).

\section{Structural Modelo}

To test how the hypothesized constructs related to one another, a eeries of structural models were run using Lisrel VI. Three structural models were initially tested in order to contrast the goodness-of-fit Indices and the significance of the beta weights between the original, primary hypothesized model and the two alternative ones. Specifically, the primary model incorporated five latent constructs. The two alternative models included four constructs. The differentiating factor was phoneme awareness. In model number one, phoneme awareness was 
distinguished by the degree of cognitive complexity the task involved -the number of steps mentally required to complete the task (oimple vB. compound). In the other two models, phoneme awareness was conceptualized as one construct, with model number two considering the relationship between working memory and phoneme awareness, and model number three excluding this relationship.

Table 6 provides a summary of the goodness-of-fit indices for the above-mentioned modela. As hypotheoized, the primary model, in contrast to the other two, best fits the data. Based on these results and confirmed by the findings in the factor analysis, an accurate distinction apparently could be made between types of phoneme awareness tasks (simple vs. compound). Whether working memory is excluded or included, however, seems to make no substantial difference in explaining the data.

Table 6.

Chi-squared Values, Goodness-of-fit Indiceg, Root Mean Square Residualg, and the Incremental fit Indices for the Initial Three structural Models

\begin{tabular}{lcccc}
\hline & $\chi^{2}$ & GFI & RMS $^{b}$ & $\operatorname{IFI}(2)\left(\chi^{2}\right)^{c}$ \\
\cline { 2 - 5 } $\begin{array}{l}\text { Yodel No. } 1 \\
\text { (Two pa factors) }\end{array}$ & $\chi^{2}(55)=89.40$ & .92 & .06 & .96 \\
$\begin{array}{l}\text { Yodel No. } 2 \\
\text { (Correlation } \\
\text { between wm/pa) }\end{array}$ & $\chi^{2}(59)=134.57$ & .87 & .08 & .90 \\
$\begin{array}{c}\text { Yodel No. 3 } \\
\text { (No correlation } \\
\text { between wm/pa) }\end{array}$ & $\chi^{2}(60)=136.02$ & .87 & .08 & .90
\end{tabular}

GFI. The amount of variance/covariance explained by the model. BMS. The average discrepancy between the elements in the ample and predicted covariance matrices.

$\operatorname{cIFI2}\left(x^{2}\right)=-\frac{x_{0}-x_{R}}{x_{0}^{2}-d f_{1}}$. The specified model is compared to the null model. The index is $^{R}$ less sensitive to sample size and violations of assumptions than $x^{\frac{2}{2}}$. An index $>.90-1.00$ represents a psychometrically sound $\mathrm{fit}$.

To further assess the relationship of the five constructs, the significance of the beta weights was examined. It was at this point in 
the analysis that difficulty was encountered in interpreting the outcome. Beta weights with high values, for example, .74 between IQ and reading, were not aignificant according to t-test results (See Appendix I). The reason for this outcome could be due to high standard error and/or a small sample size. After a number of manipulations with the parameters, and finding similar results, it was concluded that the sample size was too small to provide an accurate assessment of each construct's regression weight as it related to the others.

\section{Step-wise Multiple Regression Analyses}

Therefore, instead of relying on a structural model to explain these interrelationships, several stepwise multiple regression analyses (MRA) were implemented. The multiple regressions fell into two categories. One category examined the relationship of the constructs to one another. The second category looked at the individual predictor variables and their relationship to reading criteria. With respect to the former, each construct was determined by converting the respective manifest variable's scores into $z$-scores. ${ }^{6}$ The $z$-scores were then averaged to represent the latent construct. For example, to examine the construct of compound phoneme awareness in relation to reading performance, the scores for each of the compound awareness measures (AAT, Deletion, and Pig Latin) were converted into z-scores and then averaged to represent the construct. This technique allowed us to

${ }^{5}$ Five other structural models were run: (1) word attack as the only indicator of reading; (2) comprehension as the only indicator of reading; (3) verbal IQ as the only marker of IQ; (4) only two variables per construct (excluded blending, pig latin, and word identification tests); and (5) only two variables for each of the four constructs (IQ was excluded from the analysis). Blending and Pig Latin were removed because their loading with their respective factor was the lowest, Word Identification was removed because of its redundancy with word attack and comprehension. The reason four constructs were examined, with the exclusion of IQ, was to see if eignificant beta's would surface between those constructs by reducing the complexity of the interrelationships.

6All original manifest variables were incorporated into the analyses, including single syliable 15 seconds, even though it was initially removed from the structural model analyses. 
determine: (1) the percent of variance the constructs (i.e., predictors) accounted for within the designated criterion (e.g., reading construct) and; (2) to assess what each predictor's regression weight or contribution to the criterion was.

\section{Relationship between constructs}

The first three MRA's equally considered IQ, working memory, simple phoneme awareness, and compound phoneme awareness as predictors with (1) total reading performance as the criterion; (2) word attack as the criterion (decoding ability); and (3) passage comprehension as the criterion. Tables 7,8 , and 9 present the $R^{2}$ and Beta weights for each of the three MRA's. Figures 5 and 6 also provide a visual demonstration of the relationship between the aforementioned constructs with decoding and comprehension as separate criteria.

\section{Table 7 .}

Results of step-wibe Multiple Regression using IQ, Working Memory, simple Phoneme Awareness, and Compound Phoneme Awareness to Predict Overall Reading Performance

\begin{tabular}{|c|c|c|c|c|c|c|}
\hline step & Variable & $\mathbf{R}^{2}$ & $\begin{array}{l}\text { Change } \\
\text { in } R^{2}\end{array}$ & $\begin{array}{l}\text { Unstand. } \\
\text { b welght }\end{array}$ & $\begin{array}{l}\text { Stand. } \\
\text { error }\end{array}$ & $\begin{array}{l}\text { Stand. } \\
B \text { weight }\end{array}$ \\
\hline 1 & $\begin{array}{l}\text { Compound } \\
\text { P. A. }\end{array}$ & .44 & .44 & .32 & .03 & $.59^{* 1 * t}$ \\
\hline 2 & IQ & $.51 a^{k k k}$ & .06 & .33 & .08 & $.26^{* * *}$ \\
\hline & $\begin{array}{l}\text { Working } \\
\text { memory }\end{array}$ & -- & -- & .04 & -- & -- \\
\hline & $\begin{array}{l}\text { simple } \\
\text { P. A. }\end{array}$ & -- & -- & -.01 & -- & -- \\
\hline
\end{tabular}

As noted in the tables and figures, compound phoneme awareness made a substantial contribution to overall reading performance and, separately, to decoding and comprehension. Compound phoneme awareness 
accounted for 448 of the variance in overall reading ability, which was a highly significant portion of the variance. It, similarly, accounted for 428 of the variance in decoding and 248 of the variance in comprehension.

Table 8.

Results of Step-wise Multiple Regression using IQ, Working Memory, Simple Phoneme Awareness, and Compound Phoneme Awareness as Predictors of Decoding Performance

\begin{tabular}{|c|c|c|c|c|c|c|}
\hline step & Variable & $\mathrm{R}^{2}$ & $\begin{array}{c}\text { Change } \\
\text { in } R^{2}\end{array}$ & $\begin{array}{l}\text { Unstand. } \\
\text { b weight }\end{array}$ & $\begin{array}{l}\text { Stand. } \\
\text { error }\end{array}$ & $\begin{array}{l}\text { Stand. } \\
B \text { weight }\end{array}$ \\
\hline 1 & $\begin{array}{l}\text { Compound } \\
\text { P. A. }\end{array}$ & .42 & .42 & .31 & .04 & $.57^{m m k}$ \\
\hline 2 & $\begin{array}{l}\text { simple } \\
\text { P. A. }\end{array}$ & .43 & .01 & .10 & .06 & .12 \\
\hline 3 & IQ & $.44^{* * *}$ & .01 & .14 & .09 & .11 \\
\hline & $\begin{array}{l}\text { Working } \\
\text { memory }\end{array}$ & $-\infty$ & - & .01 & -- & -- \\
\hline
\end{tabular}

Table 9.

Results of Step-wise Multiple Regression using Io, Working Memory, Simple Phoneme Awareness, and Compound Phoneme Awareness as Predictors of Passage comprehension

\begin{tabular}{clccccc}
\hline Step & Variable & $\mathrm{R}^{2}$ & $\begin{array}{c}\text { Change } \\
\text { in } \mathrm{R}^{2}\end{array}$ & $\begin{array}{c}\text { Unstand. } \\
\text { b weight }\end{array}$ & $\begin{array}{c}\text { Stand. } \\
\text { error }\end{array}$ & $\begin{array}{c}\text { Stand. } \\
\text { B weight }\end{array}$ \\
\hline 1 & $\begin{array}{l}\text { Compound } \\
\text { P. A. }\end{array}$ & .24 & .24 & .21 & .04 & $.40^{* * *}$ \\
2 & IQ & .38 & .13 & .42 & .09 & $.35^{* \ldots *}$ \\
3 & $\begin{array}{l}\text { Norking } \\
\text { Memory }\end{array}$ & .39 & .01 & .09 & .06 & .10 \\
4 & $\begin{array}{l}\text { Simple } \\
\text { P. A. }\end{array}$ & .39 & .00 & -.06 & .06 & -.08 \\
\hline
\end{tabular}

$R^{2}$ at finel step, $F(4,135)=21.37$

p<.05 p<.01 p<.001 


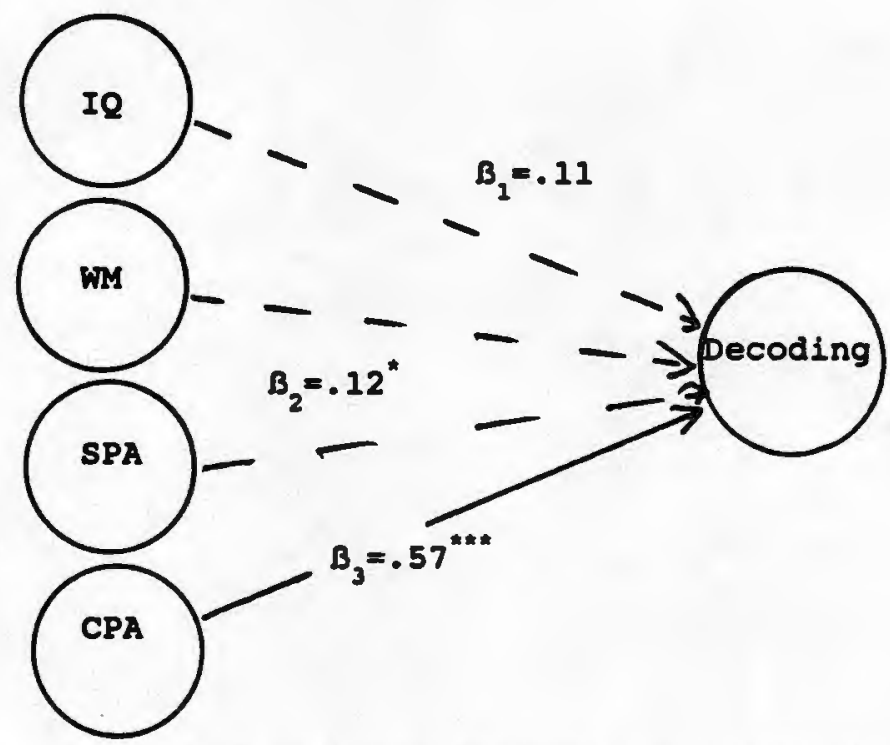

Figure 5. Beta weights of pathways between four predictor constructs with decoding.

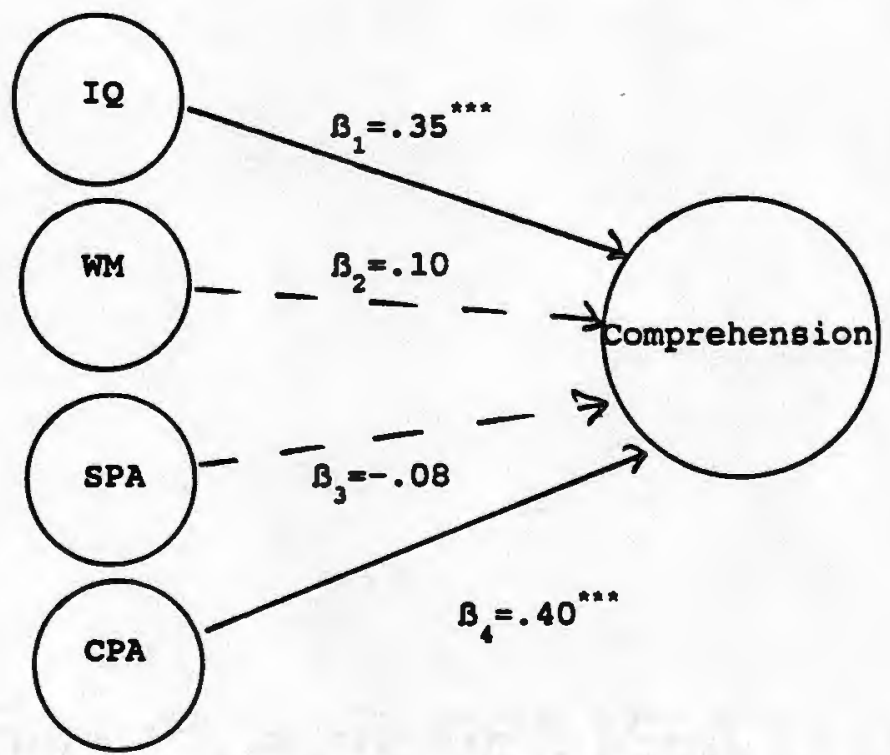

Figure 6. Beta weights of pathways between four predictor constructs with comprehension.

Decoding relied less on vocabulary knowledge (verbal IQ) and analytical skill (as evidenced in pattern analysis) than did comprehension. IQ accounted for a significant amount of independent variance $(138), F(4,135)=22.24, p<.001$, in reading comprehension. (It entered at the second step of the MRA and was weighted significantly, 
$B=.35, p<.001$ ). In contrast, IQ accounted for 1 of the variance, $F(3,136)=2.71, p<.05$, in decoding and entered after the phoneme awareness constructs.

simple phoneme awareness tasks displayed a unique relationship to the two different reading processes. With decoding, simple phoneme awareness contributed an additional 18 of the variance, subsequent to compound phoneme awareness. This amount was viewed as significant at $F(3,136)=2.93, p<.05$. ItB standardized beta weight for the regression equation was also eignificant at $p<.05(B=.12)$. With respect to comprehension, Bimple phoneme awareness entered the equation last, accounting for a nonsignificant amount of variance, and had a nonsignificant, negative weight.

In spite of the initial hypothesis, working memory made a minimal contribution to decoding and comprehension but impacted on each differently. With decoding as the criterion, memory never entered the regression equation. At the zero order level, with the MRA, the F-ratio for memory was Bignificant at p<.05. Once the influence of compound phoneme awareness was removed, the F-ratio dropped substantially indicating working memory to be of little predictive Bignificance. With comprehension as the criterion, working memory entered the equation in the third step contributing 18 of the variance, which was not significant, $F(4,135)=1.87$, with a nonsignificant Beta weight of .10 . When examining the F-ratios at each step, working memory made a significant contribution to comprehension before IQ was removed from the regression equation, $F(1,138)=6.9, p<.01$, with CPA entering the equation first. Once IQ entered the equation at the second step, the role of memory was tremendously reduced, $F(2,137)=1.84, p>.05$. Thus, working memory, apparently, was not an essentlal element in decoding ability and, once the effects of IQ were removed, did not make a significant contribution to reading comprehension, even though it ahared 18 of the variance. 
Therefore, the best predictive equation for decoding performance need only include compound and simple phoneme awareness measures to account for 438 of the variance. The better a child performs on the phoneme awareness tests the better he or she is likely to do in decoding.

The best predictive equation for comprehension would include compound phoneme awareness scores and IQ, accounting for 388 of the variance. Thus, a child's vocabulary level, nonverbal analytical skill, and awareness of phonemes at a more complex level (perhaps decoding ability), are likely to be good indicators of his or her level of text comprehension.

Given a composite IQ was used in the above regression analyseg, six more step-wise MRA's were conducted to assess the differences verbal and nonverbal components of $I Q$ make in the reading process. The correlation between the two IQ measures was low $(r=.16)$ and the cognitive processing requirements clearly differ. Table 10, 11, and 12 provide a summary of the results.

As in the other MRA, compound phoneme awareness was the predominant construct which accounted for most of the variance in overall reading (448). These findings confirmed the results of the factor analysis in which compound phoneme awareness and reading shared such a strong relationship with one another that they factored together. overall reading performance also significantly involved verbal knowledge, as well as nonverbal, analytical ability (F-ratio of .04 and .03 for individual $\mathrm{R}^{2}$ 's were significant at $\mathrm{p}<.001$ ).

Working memory, as measured in this study, took a significant drop in its contribution to overall reading once verbal or nonverbal IQ was entered into the regression analysis. [Apparently, verbal IQ reduced the influence working memory had on reading more than nonverbal IQ did. The partial correlations and F-ratio changed Blightly when nonverbal IQ entered the equation (e.g., F-ratio changed from 3.54 to 2.6 ) versus a greater change when verbal IQ was entered (e.g., F-ratio changed from 
Table 10.

Results of Step-wise Multiple Regression using Vocabulary as a Marker IQ, and, Separately, Pattern Analysis as a Marker of IQ, and Working Memory, Simple Phoneme Awareness, and Compound Phoneme Awareness as Predictors of Overall Reading Performance

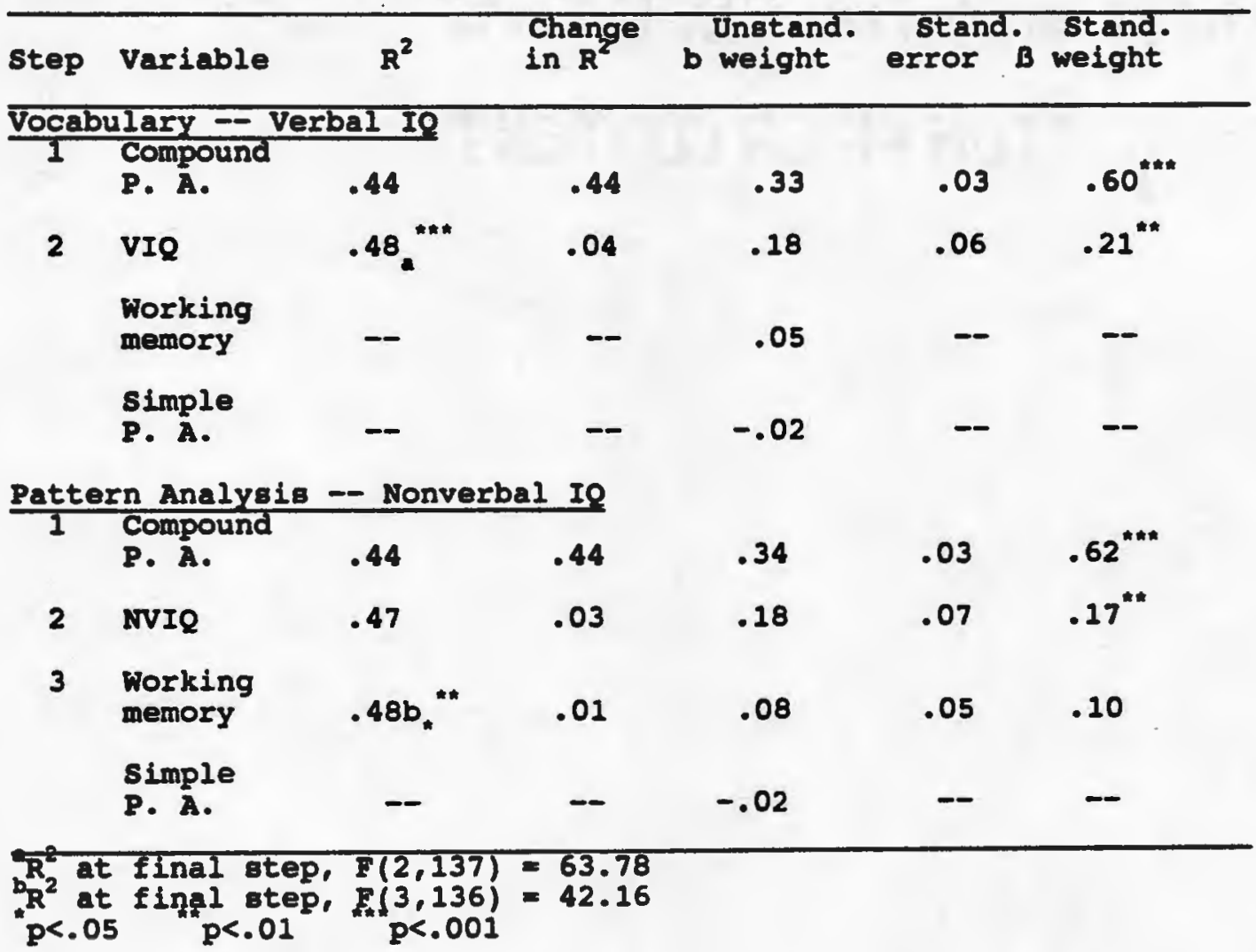

3.54 to .9).] The only difference between the two equations was that working memory added 18 variance when nonverbal IQ was used; however, this variance made a nonsignificant contribution.

simple phoneme awareness was the least related to overall reading performance of the four constructs. This outcome paralleled the findings in our first MRA (unstandardized beta weight of -.02 )

Therefore, in the MRA which examined overall reading performance, compound phoneme awareness and IQ were the most significant predictors of reading with the final $\mathrm{R}^{2}$ in each case having accounted for 488 of the variance (working memory contributing 1 when nonverbal IQ acted as the Indicator for $I Q)$. However, the inclusion of verbal and nonverbal 
Table 11.

Results of Step-wise Multiple Regression using Vocabulary as a Marker IQ, and, Separately, Pattern Analysis as a Marker of IQ, and Working Memory, Simple Phoneme Awareness, and Compound Phoneme Awareness as Predictors of Decoding Performance

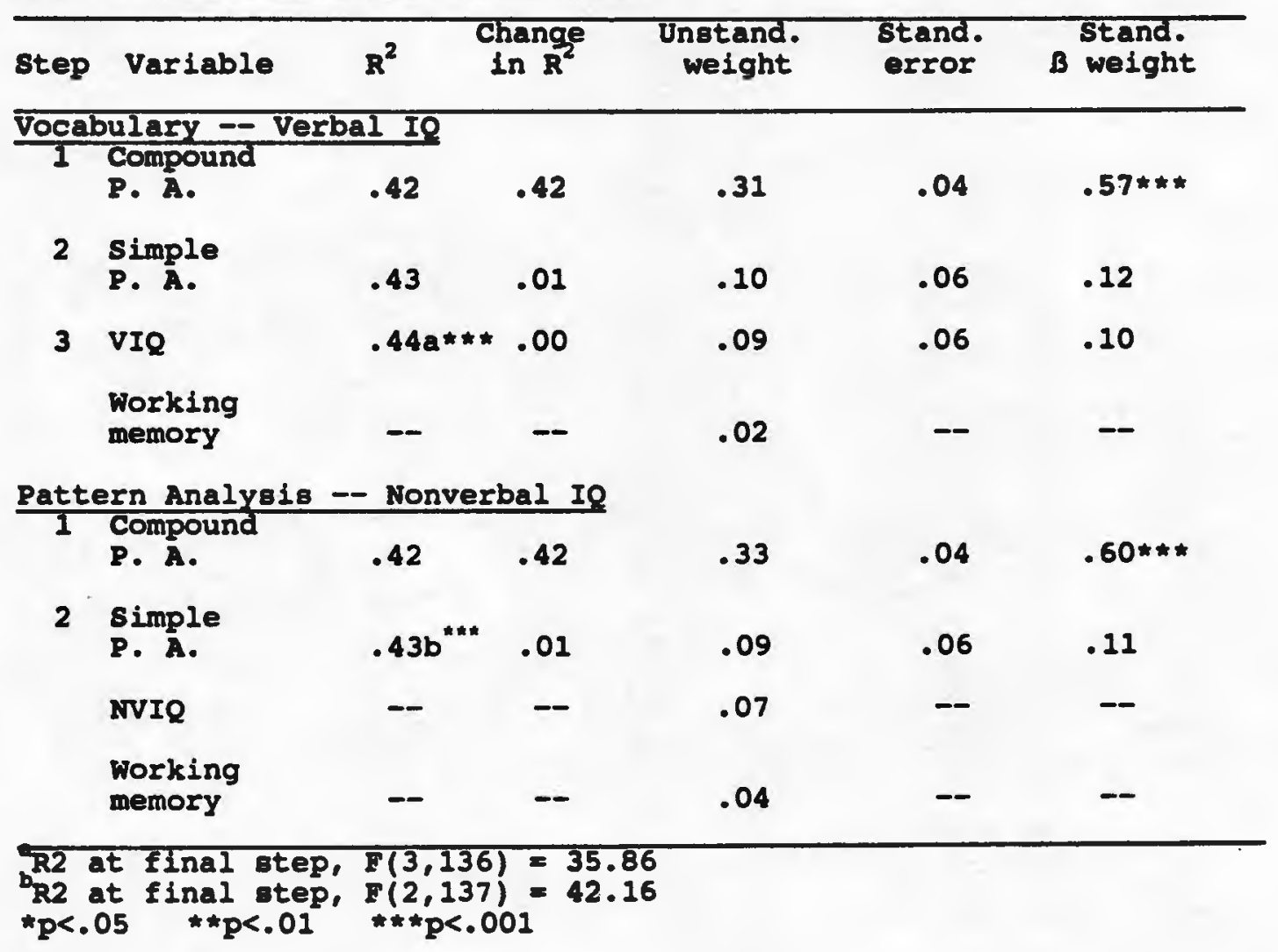

IQ measures (versus only one of them) provided a better predictive equation for overall reading performance as observed in the first MRA (518 of the variance accounted for). A second grader's overall reading performance seems best determined by his or her performance on compound phoneme awareness tasks as well as performance on the verbal and nonverbal IQ measures in combination.

Because of our interest in the components of reading we further analyzed the contribution of the constructs to decoding and comprehension with verbal and nonverbal IQ as independent markers of IQ. As noted in Table 11, decoding was primarily influenced by performance on compound phoneme awareness measures. It accounted for 428 of the 
Table 12 .

Results of Step-wise Multiple Regression using Vocabulary as a Marker IQ, and, Separately, Pattern Analysis as a Marker of IQ, and Working Memory, Simple Phoneme Awareness, and Compound Phoneme Awareness as Predictors of Comprehension Performance

\begin{tabular}{|c|c|c|c|c|c|c|}
\hline step & Variable & $\mathbf{R}^{2}$ & $\begin{array}{l}\text { Change } \\
\text { in } R^{2}\end{array}$ & $\begin{array}{l}\text { Unstand. } \\
\text { b weight }\end{array}$ & $\begin{array}{l}\text { Stand. } \\
\text { error }\end{array}$ & $\begin{array}{l}\text { Stand. } \\
B \text { weight }\end{array}$ \\
\hline \multicolumn{7}{|c|}{ Vocabulary - Verbal Io } \\
\hline & $\begin{array}{l}\text { Compound } \\
\text { P. A. }\end{array}$ & .24 & .24 & .23 & .04 & $.43 \pitchfork \star \star$ \\
\hline 2 & VIQ & .32 & .08 & .20 & .06 & $.24^{* * *}$ \\
\hline 3 & $\begin{array}{l}\text { Horking } \\
\text { memory }\end{array}$ & .33 & .01 & .10 & .06 & .13 \\
\hline 4 & $\begin{array}{l}\text { Simple } \\
\text { P. A. }\end{array}$ & $.33^{2 * n *}$ & .00 & -.07 & .06 & -.08 \\
\hline \multicolumn{7}{|c|}{ Pattern Analysis - Nonverbal Io } \\
\hline 1 & $\begin{array}{l}\text { Compound } \\
\text { P. A. }\end{array}$ & .24 & .24 & .24 & .04 & $.46^{\text {AnAn }}$ \\
\hline 2 & NVIQ & .32 & .08 & .28 & .08 & $.26^{\cdots \cdots}$ \\
\hline 3 & $\begin{array}{l}\text { Working } \\
\text { memory }\end{array}$ & .35 & .03 & .13 & .06 & $.17^{*}$ \\
\hline 4 & $\begin{array}{l}\text { simple } \\
\text { P. A. }\end{array}$ & $.35^{b=n}$ & .00 & -.07 & .06 & -.09 \\
\hline $\begin{array}{l}\mathrm{R2} \\
\mathrm{R2} \\
\mathrm{p} 2 .\end{array}$ & $\begin{array}{l}\text { It final st } \\
\text { it final st } \\
5 \text { r p<. } 0\end{array}$ & & $\begin{array}{l}135)= \\
1351= \\
.001\end{array}$ & $\begin{array}{l}96 \\
47\end{array}$ & & \\
\hline
\end{tabular}

variance. Vocabulary knowledge, nonverbal analytical ability and working memory did not make any significant contributions to it. In contrast, as indicated in Table 12, compound phoneme awareness, verbal abllity, nonverbal ability, and working memory all made independent bignificant contributions to comprehension. When incorporating verbal IQ, the $\mathrm{R}^{2}$ at the final step was .33. When only uaing nonverbal IQ, the R2 at the final step was .35.

since compound phoneme awareness entered the MRA first in all instances, we could not determine the degree IQ or working memory conceptually contributed to it. Therefore, two additional analyees were run with IQ and working memory as predictors and compound phoneme 
awareness, and simple phoneme awareness separately, as the criteria. ${ }^{7}$

Table 13 summarizes the findings. Figure 7 demonstrates the relationship between these constructs.

Table 13.

Results of Step-wise Multiple Regression using IO and Working Memory as Predictors of Compound Phoneme Awareness, and separately, simple Phoneme Awareness

\begin{tabular}{|c|c|c|c|c|c|c|}
\hline step & Variable & $\mathrm{R}^{2}$ & $\begin{array}{l}\text { Change } \\
\text { in } R^{2}\end{array}$ & $\begin{array}{l}\text { Unstand. } \\
\text { b weight }\end{array}$ & $\begin{array}{l}\text { Stand. } \\
\text { error }\end{array}$ & $\begin{array}{l}\text { Stand. } \\
B \text { weight }\end{array}$ \\
\hline \multicolumn{7}{|c|}{ Compound Phoneme Awareness } \\
\hline 1 & IQ & .08 & .08 & .52 & .20 & $.22^{* \prime \prime}$ \\
\hline 2 & $\begin{array}{l}\text { Working } \\
\text { memory }\end{array}$ & .10 & .02 & .25 & .13 & .16 \\
\hline \multicolumn{7}{|c|}{ Simple Phoneme Awareness } \\
\hline 1 & $\begin{array}{l}\text { Working } \\
\text { memory }\end{array}$ & .01 & .01 & .09 & .08 & .09 \\
\hline & IQ & -- & -- & .05 & - & -- \\
\hline
\end{tabular}

$R_{2}^{2}$ in Einal atep, $F(2,137)=7.74$

$\mathrm{R}^{2}$ in fingl step, $F(1,138)=1.13$

p<.05 p<.01 p<.001

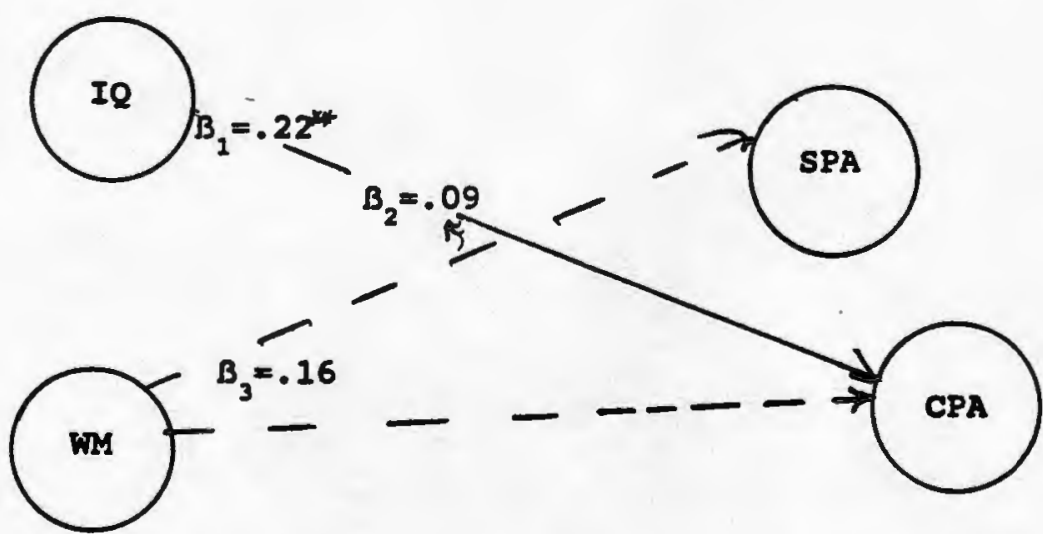

Figure 7. Beta weights of pathways for IQ and working memory with simple and compound phoneme awareness as separate criteria.

7 Since we know that compound and simple phoneme awareness share a moderately significant relationship with one another, they were not included as a predictor variable for the other (see measurement model). The primary interest was to assess the degree working memory and Io contributed to the individual phoneme awareness tasks. 
As noted in Table 13, IQ accounted for 88 of the variance while working memory accounted for 28 of the variance in compound phoneme awareness. Both percentages were signiflcant (IQ: $F(2,137)=6.84$, p<.001; WM: $F(2,137)=3.66$, p<.05). However, neither of their Beta weights were significant. Therefore, neither IQ nor working memory bear a moderate to strong relationship with compound phoneme awareness measures. These results also enhance the validation of compound phoneme awareness, suggesting it is less confounded by other abilities (1.e., memory and verbal/nonverbal IQ), and attests to its independence as a construct.

Neither IQ nor working memory displayed any relationship to simple phoneme awareness. Working memory, entering the equation first, only accounted for a nonsignificant portion of the variance (18).

In conclusion, the above series of MRA's has shown that compound phoneme awareness was a very significant predictor of overall reading performance, decoding ability, and passage comprehension. Also, compound phoneme awareness was minimally confounded by working memory or IQ. In subsequent regression steps, simple phoneme awareness was a predictive variable for decoding but of very limited value with comprehension. With comprehension, verbal and nonverbal IQ made a significant contribution. In most cases, working memory did not surface as a predictor of reading, except with comprehension, wherein it only contributed to 18 to 38 of the variance.

Relationship between manifest variables.

The above analyses gave us a good indication of how the constructs related to one another. Additional analyses were conducted to assess the predictive quality of the individual manifest variables in relation to decoding and comprehension, separately.

A step-wise MRA was used, with verbal IQ forced in first, and all remaining predictor variables given equal levels for removal or entry into the MRA. Word attack and comprehension were the criterion measures 
in two separate analyses. Tables 14 and 15 provide a summary of the results.

Table 14.

Results of Step-wise Multiple Regression with Word Attack as the Criterion, Verbal IQ Forced in First, and all Remaining Variables as Predictorg

\begin{tabular}{|c|c|c|c|c|c|c|}
\hline Step & Varlable & $\mathbf{R}^{2}$ & $\begin{array}{l}\text { Change } \\
\text { in } R^{2}\end{array}$ & $\begin{array}{l}\text { Unstand. } \\
\text { b weight }\end{array}$ & $\begin{array}{l}\text { Stand. } \\
\text { error }\end{array}$ & $\begin{array}{l}\text { Stand. } \\
B \text { weight }\end{array}$ \\
\hline 1 & VIQ & .07 & $.07 a^{* n k}$ & .06 & .06 & .07 \\
\hline 2 & AAT & .43 & $.36^{n * n}$ & .27 & .04 & $.52^{* * *}$ \\
\hline 3 & Pig Lat. & .47 & $.04^{* * *}$ & .07 & .02 & $.20^{* * *}$ \\
\hline 4 & Count & .48 & .01 & .05 & .04 & .09 \\
\hline \multirow[t]{4}{*}{5} & $\begin{array}{l}\text { Eamiliar } \\
\text { is }\end{array}$ & $.48_{b}^{* * *}$ & .00 & .05 & .05 & .07 \\
\hline & $\begin{array}{l}\text { Yopp } \\
\text { Blend } \\
\text { NVIQ } \\
\text { Delete } \\
\text { single }\end{array}$ & $\begin{array}{l}=- \\
\overline{--}\end{array}$ & $=$ & $\begin{array}{l}.03 \\
.02 \\
.01 \\
.01\end{array}$ & $\begin{array}{l}=- \\
\overline{--}\end{array}$ & $=$ \\
\hline & $\begin{array}{l}\text { Syllable } \\
\text { Nonsense }\end{array}$ & - & - & .01 & - & - \\
\hline & Ws & - & -- & -.00 & -- & -- \\
\hline
\end{tabular}

Percent of variance considered significant

$R^{2}$ at Elngel step, $F(5,134)=24.69$

p<. $05 \quad$ p $<.01 \quad$ p $<.001$

The predictor variables distributed themselves somewhat

differently with word attack and comprehension. With word attack as the criterion, verbal IQ accounted for a significant portion of variance (78) but had an insignificant regression weight assigned to it. Once the effects of verbal IQ were removed, AAT, a compound phoneme awareness task, accounted for 368 of the variance with a oignificant Beta weight of .52. Another compound phoneme awareness measure, Pig Latin, contributed an additional 48 variance and also had a agnificant Beta weight. The counting and familiar word epan measures were last to enter the equation contributing an insignificant amount of variance to the overall $\mathrm{R}^{2}$. With the inclusion of VIQ, AAT, and Pig Latin, 47 of a 
Table 15.

Results of Step-wise Multiple Regression with Comprehension as the Criterion, Verbal IQ Forced in First, and all Remaining Variables as Predictors

\begin{tabular}{|c|c|c|c|c|c|c|}
\hline step & Variable & $\mathrm{R}^{2}$ & $\begin{array}{l}\text { Change } \\
\text { in } R^{2}\end{array}$ & $\begin{array}{l}\text { Unstand. } \\
b \text { weight }\end{array}$ & $\begin{array}{l}\text { Stand. } \\
\text { error }\end{array}$ & $\begin{array}{l}\text { Stand. } \\
\text { B weight }\end{array}$ \\
\hline 1 & VIQ & .16 & .16 & .16 & .06 & .19 \\
\hline 2 & AAT & .30 & $.14^{m * *}$ & .16 & .04 & $.31^{* * *}$ \\
\hline 3 & NVIQ & .35 & $.05^{* * *}$ & .23 & .07 & $.22^{k *}$ \\
\hline 4 & Pig Lat. & .38 & $.03^{* * *}$ & .07 & .02 & $.20^{* \# *}$ \\
\hline 5 & $\begin{array}{l}\text { Familiar } \\
\text { Ws }\end{array}$ & .40 & $.02^{* \star \star}$ & .11 & .05 & $.15^{\prime \prime}$ \\
\hline 6 & Yopp & $.41_{b}^{\star \star \star}$ & .01 & -.04 & .04 & -.08 \\
\hline & $\begin{array}{l}\text { Single } \\
\text { Syllable } \\
\text { Nonsense } \\
\text { Ws } \\
\text { Delete } \\
\text { Count } \\
\text { Blend }\end{array}$ & $\begin{array}{l}-- \\
-- \\
-- \\
--\end{array}$ & $\begin{array}{l}-- \\
-- \\
-- \\
--\end{array}$ & $\begin{array}{r}.01 \\
.00 \\
-.01 \\
-.01 \\
-.03\end{array}$ & $\begin{array}{l}-- \\
-- \\
-- \\
--\end{array}$ & $\begin{array}{l}-- \\
-- \\
-- \\
--\end{array}$ \\
\hline
\end{tabular}

Percent of variance considered significant

$R^{2}$ at final step, $F_{t}(6,133)=15.21$

p<.05 p<.01 p<.001

second graders decoding performance was accounted for.

In contrast, with passage comprehension, nonverbal IQ and familiar word span were significant contributors to the regression equation. VIQ was entered first accounting for 168 of the variance. AAT contributed another 148 (versus 368 with decoding). Then nonverbal IQ entered in at the third step accounting for a significant 58 of the variance. Pig Latin accounted for 38 and then Familiar Word Span accounted for an additional 28. Only the Beta weights for the compound phoneme awareness tasks -- AAT and Pig Latin -- were significant. Therefore, in this instance, five predictor variables accounted for 408 of the variance in passage comprehension but only two had ignificant regression coefficients assigned to them.

Bssentially, comprehending text is a more complex process then decoding words. As indicated in this study, it apparently involves, at 
a near equivalent level, adequate word knowledge and compound phoneme awareness, nonverbal analytical ability, and some adequate degree of working memory for familiar words. Decoding nonsense words seems a more basic skill which requires awareness of phonemes at a complex level -not just a simple awareness of phonemes, per se, but the ability to mentally manipulate them -- and, less importantly, word knowledge.

Up to this point, we have gained a better understanding of how the four proposed hypothetical constructs (i.e., verbal working memory, simple phoneme awareness, compound phoneme awareness, and IQ) relate to reading and to one another, and which observed variables are preferred indicators of their construct and best predictors of decoding and comprehension. All of the above analyses incorporated a sample of subjects whose reading performance ranged in a normal distribution from poor to superior. Another important question to address was whether the relationships among the variables changed when contrasting the least skilled group of subjects with the skilled ones. For example, is a less-skilled decoder (ISK) apt to experience more problems with memory tasks than a skilled decoder (SK)? Or, do simple phoneme awareness task significantly discriminate these reading groups even though simple phoneme awareness plays a minor role in decoding for most second graders? Bssentially, on which variables do the profiles of these two reading groups differ? Is there a difference in how the observed variables relate to decoding performance in these subgroups or does the relationship remain relatively the same?

\section{Analysis-of-Covariance}

To partially answer the above questions, six analyses-ofcovarlance (ANCOVA) were run. The ISR and SK decoding groups were selected based on their decoding ability (independent variable). The LSR decoders' standardized scores ranged from 76 to 89 ( $n=24$, grade equivalent: 1.2 to 1.8 , age equivalent: 6 yrs. 5 mos. to 7 yrs. 0 mos.). The SR decoders' standardized scores ranged from 111-123 ( $n=25$, 
grade equivalent: 3.7 to 6.7 , age equivalent: 9 yrs. 1 mo. to 11 yrs. 11 mos.). Composite IQ was covarled out from all of the analyses. The dependent variables were AAT, Counting, Yopp, Nonsense Word Span and Familiar Word Span (with and without order of recall), and single syllable Memory-15 seconds. The results for each aNcova can be found in Table 16.

With IQ covaried out, verbal memory measures did not significantly discriminate reading groups, which supported the findings of the prior analyses. (Some additional analyses were run in which rerbal Io and nonverbal IQ were separately covaried out. When verbal IQ was covaried out working memory measures did not discriminate decoding groups. Familiar Word Span did, however, approach significance, $F(1,49)=3.79$, $p=.06$. Similarly, when nonverbal Io was covaried, none of the memory measures significantly discriminated groups. These additional findings provided further confirmation of our prior results, in that working memory was minimally related to decoding skill.)

In contrast, simple phoneme awareness tasks did significantly differentiate reading groups, with Yopp significant at $F(1,46)=21.17$, pe.001, and counting proving significant at $F(1,46)=7.48, p<.01$. This finding supports the notion that ISR decoders are deficient in basic phoneme awareness skills in spite of simple phoneme awareness measures being lese strongly linked with reading proficiency among our larger sample of second graderB. And, lastly, AAT, a measure of compound phoneme awareness, was a significant discriminator of decoding groups $F(1,46)=49.05, p<.001$.

Again, we find support for the conclusion that verbal working memory is not strongly related to decoding skill among second graders, whereas phoneme awareness measures are highly related to decoding performance. These latter measures are extremely sensitive variables for discriminating between ISK and SK decoders. 
Table 16.

Means and Standard Deviations for skilled and Less-skilled Decoder on Three Phoneme Awarenesg Tasks and Three Working Memory Measures, and the Respective F-ratio's with IQ as the Covariate

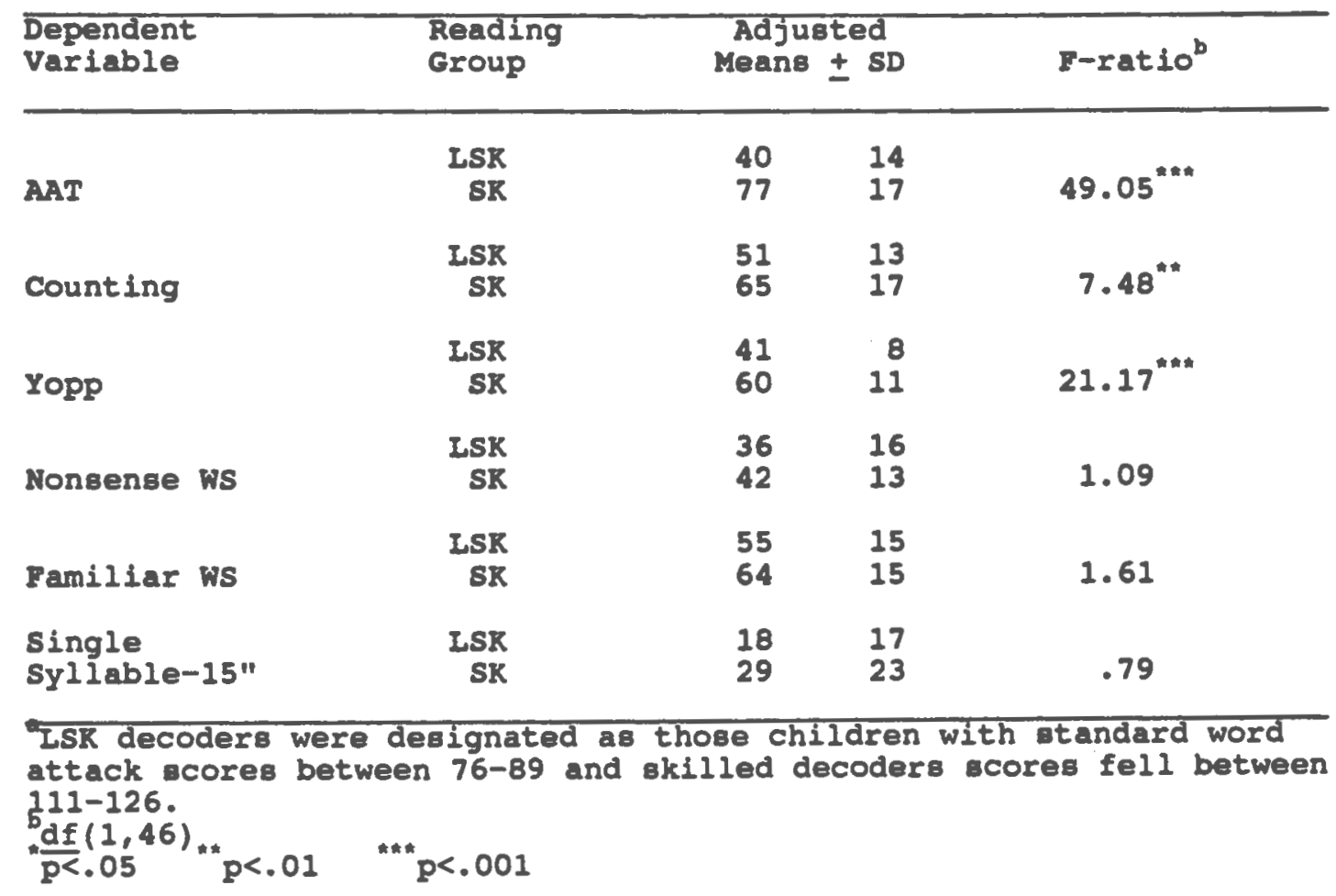


CHAPTER IV

DISCUSSION

The main goals of this study were to explore the relationship between working memory and phoneme awareness measures (simple and compound), and to investigate the relationships of these phonological processes to decoding and comprehension components of reading performance. Second-grade children whose reading skills were normally distributed served as subjects. In addition to examining performance of the entire subject pool, two subgroups of skilled and less-skilled decoders were compared to address whether a different pattern of relations was evident in children who have difficulty learning to read.

In order to investigate these questions, multiple measures were used to assess the hypothesized constructs. The first step in analyzing the results was to evaluate whether the anticipated factors were present. It is noteworthy that each manifest variable loaded into its respective latent construct, as predicted, yielding four constructs: simple phoneme awareness, compound phoneme awareness (loaded with reading), IQ, and verbal working memory. These findings supported Yopp's distinction between simple and compound levels of phonological awareness. Essentially, the six phoneme awareness tasks separated into two factors defined by degree of complexity. While these constructs were significantly related, they were best construed as two distinct factors. It is also interesting that compound phoneme awareness loaded with reading performance. Two explanations seem plausible. First, research on reading acquisition euggests a bidirectional relationship between phoneme awareness and reading skill; that is, that oach facilitates further development of the other (0.g., Perfetti, Beck, Bel1. E Hughes, 2987). Second, subjects may be inclined to use a spelling strategy to execute awareness measures, particularly if the tasks are somewhat demanding. Thus, the degree of literacy a child possesses would influence performance in reading and with compound phoneme tasks. The verbal and nonverbal Io measures factored 
together, though the low correlation between these tasks $(x=.16)$ underscores the distinct cognitive requirements of each. Lastly, the construct validity of working memory was confirmed: Three measures selected to assess verbal working memory factored together. This outcome of four separate factors supports a number of previous results indicating several, relatively independent, factors that may make unique contributions to reading acquisition and reading performance (Blachman, 1983, Mann, 1984; Pennington, et al., in press; Wagner, 1988).

Having added to the construct validity of the four factors, the next questions were concerned with how they related to each other and to reading. In particular, a central goal of this study was to determine whether working memory ability contributed to performance on phonological awareness tasks. The results indicated that at least for this stage of reading development, performance in these two domains is not significantly related. Thus, despite the memory demands of phonological awareness measures, performance on phoneme awareness tasks is determined primarily by other abilities.

On the other hand, working memory performance did correlate significantly with IQ, particularly with the vocabulary task. Gathercole and her colleagues (1990) suggest that vocabulary acquibition may be closely related to one's working memory capacity. This association between verbal memory processes and IQ raises complex questions about how to appropriately control for individual differences in general cognitive ability. If the verbal IQ task tapo many of the same cognitive processes as memory tasks do, controlling for verbal IQ may eliminate sources of variance that are theoretically relevant to an underatanding of factors influencing abilities in phonological awareness. The verbal IQ task used in the present study required the production of definitions for provided words. For second graders, this task may tax memory span, lexical retrieval, and syntactic processing, all of which make demands on memory resources. In any case, in the present study concerns about the nature of the relationship between IQ 
and working memory were addressed by controlling separately for verbal IQ and for nonverbal IQ as discussed later.

Turning to the important issue of how the factors of verbal memory, IQ, and phoneme awareness relate to reading achievement, one outcome was particularly compelling. Corroborating the research literature to date, compound phoneme awareness as a construct accounted for 428 of the variance in decoding and 248 of the variance in comprehension, entering multiple regression equations first in all instances. When examining the individual variables for this construct, AAT accounted for the greatest portion of the variance in decoding (368), and after the contribution of verbal IQ, it accounted for a unique 148 of the variance in comprehension. Thus, a child's ability to segment and manipulate phonemes in a complex way significantly related to how well he or she decoded unfamiliar words. Also, compound phoneme awareness skills were clearly linked with comprehension levels. The construct of imple phoneme awareness accounted for an additional 1 t of the variance with decoding and the respective manifest variables indicated moderate correlations with decoding ( $p<.05)$. Simple phoneme awareness tasks revealed an insignificant relationship to comprehension. Examination of the link between facility on working memory tasks and reading skill suggested a significant association when comprehension was the outcome score, but not when decoding was. Given the normal range of reading scores for the subjects in this study, it may be that once a child has mastered a certain degree of decoding proficiency, individual differences in verbal working memory do not impact on decoding performance. (This issue will be considered below when the results of the less-skilled readers are reviewed.) A study by Gathercole, et al. (submitted) reported a significant relationship between memory scores and reading skill only at very early stages of reading acquisition. The present results point to a stronger association in later years between working memory ability and reading comprehension level, although once composite IQ was included in the 
analyses, memory performance only contributed a minimal amount to variance accounted for in multiple regression analyses. Of interest, too, was the finding that when verbal IQ and nonverbal IQ were separate indicators of IO, working memory made a small but significant contribution to comprehension akill. As noted earlier, the cognitive overlap between $I Q$ and working memory measures makes the interpretation difficult. Further research is necessary to explicate the nature and degree of correspondence between memory measures and the various procedures for assessing components of verbal ability (e.g., receptive versus expressive vocabulary skill).

The construct of IQ demonstrated a significant relationship to the overall process of reading and to passage comprehension. Vocabulary knowledge explained 48 of the variance in overall reading performance and Pattern Analysis explained another 38 of the variance. IO appeared to have a greater influence on a child's comprehension level than his or her decoding skill. After the effects of phoneme awareness were eliminated in a multiple regression analysis, IO had no effect on decoding, confirming prior evidence that phonemic awareness is more critical in the acquistion of decoding skills than is general IQ (Stanovich, et al., 1983). In contrast, after compound phoneme awareness entered the predictive equation for comprehension. IQ still contributed a significant 138 of the variance. such findings support the observation of an association between vocabulary knowledge and reading ability (Vellutino scanlon, 1987) and suggest that word knowledge, vocabulary, and other IQ-related variables are eignificantly correlated with comprehension.

What is less frequently addressed is the influence of a nonverbal task such as Pattern Analysis, an index of analytical ability. Recent articles suggest that nonverbal, visual working memory tasks should be re-examined as factors influencing reading performance (e.g., stanovich, 1990). Since we did obtain a significant relationship between a nonverbal measure with comprehension, it might be worthwhile to further 
explore the influence of this variable on certain aspects of reading. To augment our understanding of how these individual variables related to the reading process, differences in performance between lessakilled and akilled decoders were also examined. A similar picture emerged from this comparison as for the entire subject pool. Reading ability was most associated with performance on the compound phoneme awareness measures. However, scores on the simple phoneme awareness measures also clearly differentiated the two decoding groups. The Yopp test was the best simple phoneme task for discriminating between the reading groups. Thus, the simple phoneme awareness construct seems to be important for early reading acquisition and for assessing decoding deficiencies. (See Adams, 1990, for a discussion of the predictive value of simple phoneme measures at the preschool and early elementary levels.) When comparing working memory ability between the two groups, no significant difference was detected.

These reaults have a number of practical implications. One important implication from this study is with respect to the matter of specificity in reading disabilities. Do reading disabled children experience a specific deficit? Is this deficit independent of IQ?

There are two independent findings in this study that support a opecific phonemic deficit that can be isolated from overall cognitive ability. Firat, our results indicated verbal/nonverbal IQ measures made a minimal contribution to decoding. However, a significant relationship surfaced between IQ and comprehension. Second, in addition to compound phoneme awareness measures differentiating less-skilled and skilled decoders, simple phoneme tasks also discriminated the two decoding groups. Even though simple phoneme awareness measures contributed very little in predicting performance on the word attack subtest across all readera, they were highly sensitive for differentiating decoding groupe. These results suggested that poor readers are impaired in processing phonemes at a very basic level -- a level most second-grade readers have already mastered. Therefore, given a more severe deficit in phoneme 
awareness among less-8killed decoders, it would be diagnostically beneficial to standardize a simple phoneme awareness measure.

By researching the relationship of the aforementioned constructs, and through the incorporation of multiple measures, we are now better able to determine which measures are best used in paychoeductional assessments given opecific referrals (e.g., reading difficulties). For example, the modified verbion of the AAT was a reliable and valid indictor of compound phoneme awareness and predicted a large percentage of variance in decoding and comprehension ability. It would serve as an excellent measure to incorporate in preschool assessments (1.e., to predict future reading performance) or to determine the nature of a child's reading problem, given norms are established. simple phoneme awareness is most 1 ikely to be a good predictor of early reading ability, as well as a more severe phoneme awareness deficit, since it discriminated the decoding groups so well.

With respect to instructional intervention, one should always be cautious about which techniques are recommended when they are based on relational research. As a result of this study and others, however, it is apparent that understanding and applying the phonemic principle to decoding words is an essential aspect of learning to read. In addition, a child's vocabulary level seems to affect comprehension of text. Within this study it is not possible to determine the directional relationship between vocabulary and reading skill. In all likelihood, they share a bidirectional relationship with one another. A good reader expands his or her vocabulary through reading and a child with an extensive vocabulary is apt to comprehend more material (Stanovich, Cunningham, west, in press). These findings suggest, first, that training on phonological awareness combined with a code-emphasis approach to reading instruction would be most valuable, especially in early stages of learning to read. second, they indicate that this instruction would be facilitated by literacy activities designed to bulld rocabulary and conceptual knowledge. 
In closing, the results of this study support a phonological processing model that conceptualizes verbal working memory and phoneme awareness as two independent processes. Further, the results confirm an extension of the model such that phoneme awareness should be defined on the basis of how cognitively demanding such tasks might be.

What emerges is a strong and consistent outcome that phoneme awareness is importantly related to reading performance with simple phoneme awareness measures more sensitive to early atages of reading acquisition. These findings support the growing evidence that instruction in phoneme awareness could provide a valuable complement to current methods of reading instruction. The relation of verbal working memory to learning to read is less clear. Here a weak association with reading auccess was attained, and that was 1 imited to performance on reading comprehension measures. The results of prior studies yield an inconsistent pattern (e.g., Brady, in press; Pennington, et al., in press). Therefore, the hypothesis that poor readers experience a general phonological coding deficit requires further investigation. We are also left with the need for better measures of working memory and inconclugive evidence as to whether to control for the effects of verbal IQ when investigating the role of working memory in reading development. However, the present study underscored the value of evaluating the contribution of phonological processes to both decoding and comprehension measures of reading skill since different relations may be present. Future longitudinal research would help delineate whether the pattern of relations differs for particular stages of reading acquisition. 
REFERENCES

Adams, M. J. (1990). Beginning to read. Cambridge, MA: MIT Pre日s.

Alegria, J., Pignot, E., \& Morais, J. Phonetic analysis of speech and memory codes in beginning readers. Memory and cognition, 10, 451-456.

Backeman, J. (1983). The role of paycholinguiatic akille in reading acquisition: A look at early readers. Reading Research quarterly, 18, 466-479.

Baddeley, A. (1986). Working memory. Oxford: Clarendon Presв.

Ball, E., Blachman, B. (1988). Phoneme segmentation training: Effect on reading readiness. Annals of Dyolexia, 38, 208-225.

Blachman, B. (1983). Are we assessing the linguigtic factors critical in early reading? Annals of Dyslexia, 33, 91-109.

Bradley, I., Bryant, P. (1983). Categorizing sounds and learning to read: A causal connection. Nature, 301, 419-421.

Brady, S. (1986). Short-term memory, phonological processes and reading ability. Annals of Dyelexia, 36, 138-153.

Brady, S. (1988, November). Is there a unitary phonological deficit? Paper presented at the meeting of the Orton Dyslexia Society, Tampa, Florida. To appear in S. Brady \& D. Shankweller (Eds.). Phonological processes in literacy. Hillodale, NJ: Erlbaum.

Brady, S., Mann, V., Schmidt, R. (1987). Errors in short-term memory for good and poor readers. Memory and cognition, 15, 444-453.

Brady, S., Shankweiler, D., Mann, V. (1983). Speech perception and memory coding in relation to reading ability. Journal of

Experimental Child Paychology, 35, 345-367.

Calfee, R., Iindamood, P., Iindamood, C. (1973). Acoustic-phonetic skills and reading - kindergarten through twelfth grade. Journal of Educational Paychology, 64, 293-298.

Cohen, R., \& Netley, C. (1981). Short-term memory deficite in reading disabled children, in the absence of opportunity for rehearsal strategies. Inteliligence, $5,69-76$.

Conners, F., Olson, R. (in press). Reading comprehension in dyslexic and normal readers: A component-skills analysis. In D. A. Balota, G. B. Flores d'ArCals, \&. Rayner (Eds.), Comprehension procesees in reading. Hillsdale, NJ: Erlbaum.

Dreyer, I. (1989). The relationship of chlldren's phonological memory to decoding and reading abllity. Unpublished doctoral diesertation, Columbia University.

Fox, R., Routh, D. (1976). Phonemic analysis and synthesis as wordattack skilis. Journal of Educational Paychology, 68, 70-74. 
Fox, B., Routh, D. (1980). Phonemic analysis and severe reading disability in children. Journal of Poycholinguistic Research, 9, 115-119.

Fox, B., \& Routh, D. (1983). Reading disability, phonemic analysis and dysphonetic spelling: A follow-up atudy. Journal of Clinical Child Prychology, 12, 28-32.

Fox, B., \& Routh, D. (1984a). MY . . . Is a little bit of mays Phonemes, reading, and spelling. Advances in Learning and Behavioral Disabilitieg, 3, 95-124.

Fox, B., Routh, D. (1984b). Phonemic analysis and gynthesis as word attack Bkills: Revisited. Journal of Educational Psychology, 76 , 1059-1064.

Gathercole, S., \& Baddeley, A. (1989). Evaluation of the role of phonological STM in the development of vocabulary in children: A longitudinal study. Journal of Memory and Language, 28, 200-213.

Gathercole, S., Millib, C., Baddeley, A. (1990). Differentiating phonological memory and awareness of rhyme: Reading and vocabulary development in children. Manuscript abmitted for publication.

coldstein, D. (1976). Cognitive-linguistic functioning and learning to read in preschoolers. Journal of Educational Psychology, 68, 680-688.

Ratz, R., Shankweller, D., Liberman, I. (1981). Memory for item order and phonetic recoding in the beginning reader. Journal of Experimental Chlld Pgychology, 32, 474-484.

Iiberman, I. (1973). Segmentation of the spoken word and reading acquisition. Bulletin of the Orton Soclety, 23, 65-77.

Liberman, I., Shankweller, D., Fischer, F., Carter, B. (1974). Explicit eyllable and phoneme gegmentation in the young child. Journal of Experimental Child Psychology, 18, 201-212.

Lundberg, I., Frost, J., \& Petersen, O. (1988). Effects of an extensive program for stimulating phonological awareness in preschool children. Reading Research Quarterly, 23, 263-284.

Mann, v. (1984). Longitudinal prediction and prevention of early reading difficulty. Annals of Dyslexia, 34, 117-136.

Mann, V., Cowin, E., \& schoenheimer, J. (1989). Phonological processing, language comprehension, and reading ability. Journal of Learning Disabilities, 22, 76-89.

Mann, V., Liberman, I. (1984). Phonological awareness and rerbal Bhort-term memory. Journal of Learning Disabilities, 17, 592-599.

Morals, J. (1987). Phonetic awareness and reading acquisition. Pgychological Research, 49, 147-152.

Oleon, R., Wise, B., Conners, F., Rack, J., \&ulker, D. (1989). specific deficits in component reading and language skillB: cenetic and Environmental Influences. Journal of Learning Disabilities, 22, 339-348. 
Pennington, B., Van Orden, G., Kirson, D., E Haith, M. (in press). What is the causal relation between verbal STM problems and dyslexia? In S. Brady \& D. Shankweiler (Eds.), Phonological processes in literacy. Hillsdale, NJ: Erlbaum.

Perfett1, C., Beck, I., Bell, L., Hughes, C. (1987). Phonemic knowledge and learning to read are reciprocal: A longitudinal study of first grade children. Kerill-Palmer Quarterly, 33, 283319.

Pratt, A., Brady, S. (1988). Relation of phonological awareness to reading disability in children and adults. Journal of Educational Psychology, 80, 319-323.

Rapala, M., B Brady, S. (In press). Reading abllity and short-term memory: The role of phonetic processing. Reading and Writing.

Rosner, J., \& simon, D. (1971). The auditory analysis test: An initial report. Journal of Learning Dibabilities, 4, 384-392.

Shankweiler, D., Liberman, I., Mark, L., Fowler, C., \& Fibcher, F. (1979). The speech code and learning to read. Journal of Experimental PBychology: Human Learning and Memory, 5, 531-545.

Share, D., Jorm, A., Maclean, R., \& Matthews, R. (1984). Sources of individual differences in reading acquistion. Journal of Educational Peychology, 76, 1309-1324.

siegel, I., E Inder, B. (1984). Short-term memory processes in children with reading and arithmetic learning disabilities. Developmental Psychology, 20, 200-207.

Snowling, M. (1981). Phonemic deficits in developmental dyslexia. Psychological Research, 43, 219-234.

Spring, C., \& Capps, C. (1974). Encoding speed, rehearsal, and probed recali of dyslexic boys. Journal of Educational Psychology, 66, 780-786.

stanovich, K. (1982). Individual differences in the cognitive processes of reading: Text-level processes. Journal of Learning Disabilities, 15, 549-554.

Stanovich, K. (1986). Explaining the variance in reading abllity in terms of psychological processes: What have we learned? Annals of Dyslexia, 35, 67-96.

Stanovich, $K$. (In press). Discrepancy definitions of reading disability: Has intelligence led us astray? Reading Research ouarterly.

stanovich, K., Cunningham, A., Cramer, B. (1984). Assessing phonological awareness in kindergarten children: Iseues of task comparability. Journal of Experimental Child Psychology, 38, 175190.

stanovich, R., Cunningham, A., Feeman, D. (1984). Intelligence, cognitive skills, and early reading progress. Reading Research puarterly, 14, 278-303. 
Stanovich, R., West, R., \& Cunningham, A. (in press). Beyond phonological processes: Print exposure and orthographic processing. In S. Brady \& D. Shankweller (Eds.), Phonological processes in literacy. Hillsdale, NJ: Eribaum.

Thorndlke, R., Hagen, E., \& sattler, J. (1986). Stanford-Binet intelligence scale: Eourth edition technical manual. Chicago, II: Riverside Publishing.

Torgesen, J. (1978-79). Performance of reading disabled children on cerial memory tasks: A selective review of recent research. Reading Research Quarterly, 14, 57-87.

Torgesen, J. (1985). Memory processes in reading disabled children. Journal of Learning Disabilities, 18, 350-357.

Torgesen, J. (1989). Cognitive and behavloral characterlstics of children with learning disabilities: Concluding comments. Journal of Learning Disabilities, 22, 166-168.

Torgesen, J., Houck, D. (1980). Processing deficiencles in learning disabled children who perform poorly on the digit span test. Journal of Educational Psychology, 72, 141-160.

Turner, M., Engle, R. (1989). Is working memory capacity task dependent? Journal of Memory and Language, 28, 127-154.

Vellutino, F. (1987). Dyslexia. Scientific American, 256, 34-41.

Vellutino, F., scanion, D. (1987). Phonological coding, phonological awareness, and reading ablilty: Ividence from a longltudinal and experimental study. Merrill-Palmer Quarterly, 33, 321-363.

Vellutino, F., Smith, H., Steger, J., Kaman, M. (1975). Reading disability: Age differences and the perceptual-deficit hypothesis. Child Development, 46, 487-493.

Wagner, R. (1986). Phonological processing abilities and reading: Implications for disabled readers. Journal of Learning Disabilities, 19, 623-630.

Wagner, R. (1988). Causal relations between the development of phonological processing abilities and the acquisition of reading okills: A meta-analysis. Merr111-Palmer puarterly, 34, 261-279.

wagner, R., Balthazor, M., Hurley, S., Morgan, S., Rashotte, C., Shaner, R., simmons, $\mathbf{K}$., stage, $\mathbf{S}$. (1987). The nature of prereaders' phonological processing abilities. Cognitive Development, $2,355-$ 373.

Wagner, R., Torgesen, J. (1987). The nature of phonological processing and its causal role in the acquisition of reading ak111. Peychological Bulletin, 101, 192-212.

Hilliams, J. (1980). Teaching decoding with an emphasis on phoneme analysis and phoneme blending. Journal of Educational Peychology, 72, 1-15.

Woodcock, R. (1987). Woodcock reading mastery tegts-Revised. Circle Pines, vN $z$ American Guidance service. 
Yopp, B. (1988). The validity and reliability of phonemic awareness test 8. Reading Research Quarterly, 23, 159-177. 


\section{APPENDIX A}

\section{SEGMENTATION TEST}

Instructions: I'm going to say a real word and I want you to tell me what sounds you hear in the words -- not letters. For example, in the word "cat," there are three sounds -- $/ \mathrm{c} /$, an $/ \mathrm{a} /$, and $\mathrm{a} / \mathrm{t} /$. Now, when you say the sounds, I want you to say them slowly and far apart from each other like I did with the word "cat." Now, let's try some together.

Practice: go, man, fish.

(After each item say: What are the smallest sounds you hear? If the child 18 wrong with the practice trials, tell him/her how many sounds there are and ask him/her to try again. If still incorrect, give correct Ive feedback.)

Now, I'm going to say some more words and I want you to tell me their separate sounds. Listen carefully! (Do not correct child with test items. Repeat word only once if child requests.)

(Items were presented in random order.)

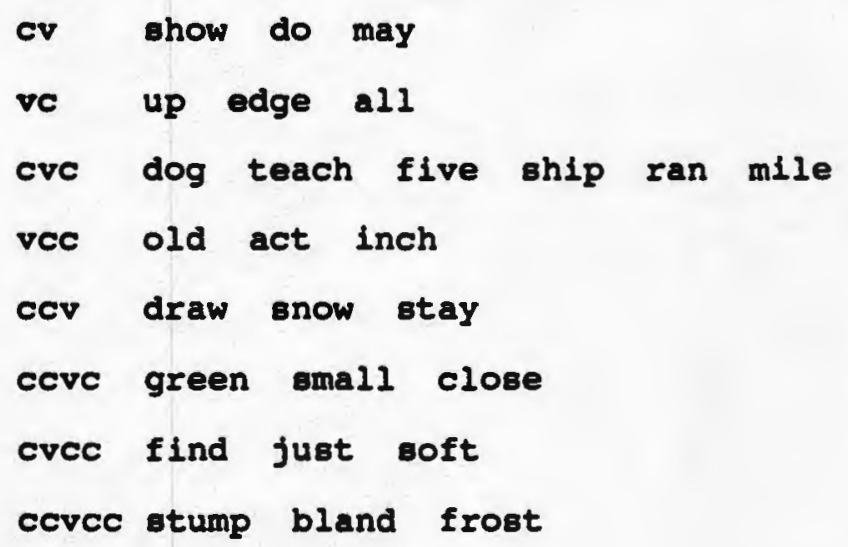


APPENDIX B

SEGMENTATION COUNTING TEST

Instructions: Here's a card and ten tiles. I'm going to say some words that aren't real words and I want you to show me how many sounds you hear in the words -- not letters but sounds. You'll show me how many sounds there are by placing the same number of tiles on this card. For example, with the word /ot/, there are two sounds $/ 0 /$ and $/ t /, 80$ I'll place two tiles on this card. OR, now let's try some together.

Practice: How many sounds do you hear in the word "ru?" You hear two sounds. What are they? (If child says the letters, correct $\mathrm{him} / \mathrm{her}$ and say: I want you to give me the sounds, not the letters. OR, now how many tiles would you put on your card? (correct) continue with the same instructions for: tat and pog.

Now, I'm going to say some more words and I want you to count the number of sounds you hear so listen carefully. (Correct child on practice trials only. Do not correct child with test items. Repeat word only once if child requests. Make sure the card is cleared away before each item.)

(The items below were randomly presented.)

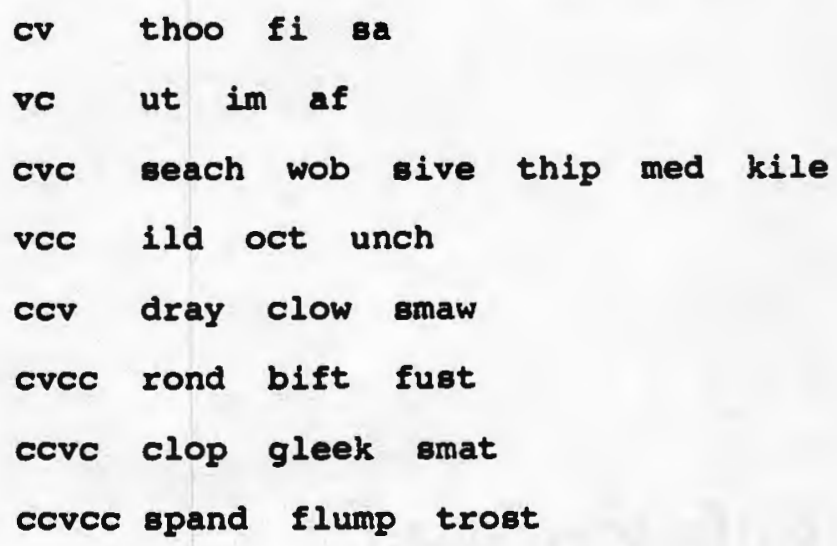




\section{APPENDIX C \\ PHONEME BLENDING TEST}

Instructions: Now you will hear me say a word in smaller parts -their separate sounds. I want you to put the sounds together to make a real word. For example, if you heard the sounds $/ \mathrm{c} /, / \mathrm{a} /$, and $/ \mathrm{t} /$ and put them together, it sounds like "cat." Now, let's try some together.

Practice: (Present phonemes at two second intervals.)

u-p (What word do these sounds make?)

b-oo-k

d-u-ck

Now, on this tape you will hear more sounds that I want you to put together to make real words. Iisten carefully and say the word after you hear the sounds. (Do not repeat items. State only once. If the child does not respond after hearing the sounds ask, "what word is it?") (The items below were presented in the order given.)

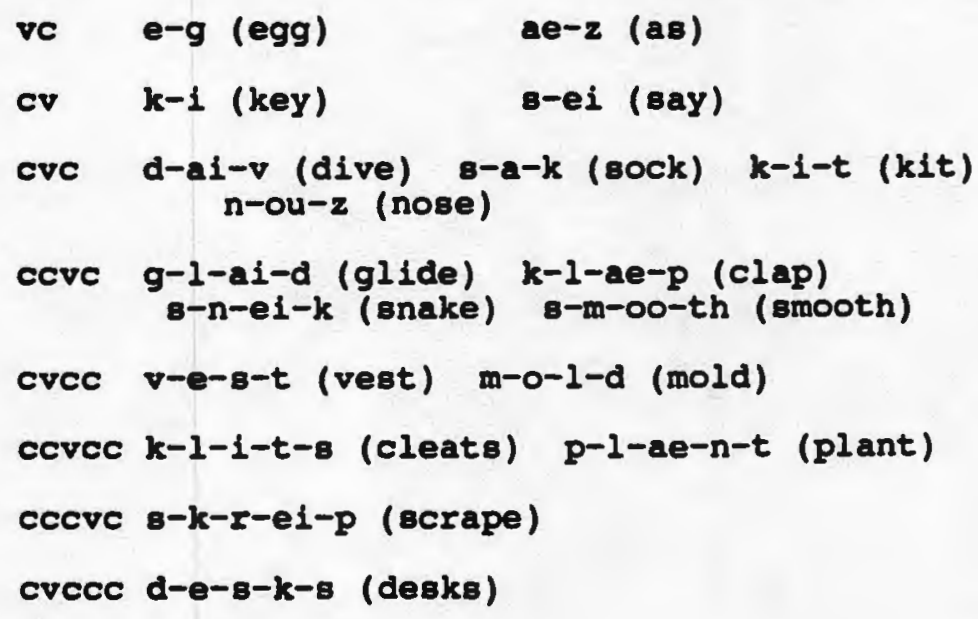


APPENDIX D

AUDITORY ANALYSIS TEST

Instructions: Now, on this test I'm going to want you to say a word without saying part of it. For example, can you say cowboy without saying boy? OR, now let's try some more.

Practice: (1) say homework without saying home

(2) Bay rug without saying /g/

(3) Bay chair without saying / ch/. 1tems.)

(Give corrective feedback on practice trials but not on test

Now, let's do some more. Iisten carefully.

(Items below presented randomly.)

Initial Consonant
(m) an
(w) $i 11$
(g) ate
(c) lip
(8)mile
(b) lock
(b) reak
(t)rail
(g)rain
$(\mathrm{sh})$ rug
(o)train (g) low

Final Consonant

bel(t) ro(de) to(ne) ti(me) plea(se) stea(k)

Medial Consonant

$B(m) e l l \quad c(x)$ eate $B(m)$ ack $\quad s(k)$ in $\quad$ st $(r)$ eam $c(1)$ utter 


\section{APPENDIX E}

DELETION TEST

Instructions: On this test I'm going to say a word, but not a real word, and have you say it without saying part of it. For example, can you say "mowcoy" without saying /mow/? OR, let's try some more.

Practice: (1) bafmot without saying /mot/

(2) ko without saying $/ 0 /$

(3) pim without saying $/ p /$. items.)

(Give corrective feedback on practice trials but not on test

Now, let's do some more. Listen carefully.

Initial Consonant
(1) an (d) ilt
(j) ate
(th) rike
(8) lote
(c) raik

(b) Iun

(t) row

(g) lowt

(B) tope

(d) roon

(b) lirg

Final Consonant
mu (n) sa(de)
ha (ne)
$\operatorname{nis}(t)$
ril(k)
$\operatorname{pril}(t)$

Medial Consonant
Bc(r)eel
$t(r)$ up
$B(m)$ ake
$c(x)$ ite
c(1) isk
$B(n) 00 k$ 


\section{APPENDIX $\mathbf{F}$}

PIG LATIN TEST

Instructions: On this test I will be saying a word that I want you to say without its first sound. I also want you to say another word by adding the first sound you hear to the /a/ sound -- long a. So, let's practice this first. If I say the word "so" you would say o-say. You would take away the $/ 8 /$ Bound and have the $/ 0 /$ left. Then you would add it to the /ay/. Then put it all together and you get -- osayl Now, let's try some together for practice.
(1) go (o-gay)
(2) do (o-day)
(3) me (e-may)
(4) be (e-bay)
(5) red (ed-ray)

(6) blend (lend-bay)

(Give corrective feedback on practice trials only. If the child gets two correct go on with the test items. Otherwise, stop. If necessary, give corrective feedback on item 1 below and then go on to 12. If the child cannot do 2 - stop administering the test.)

Alright, now I'm going to give you some more so listen carefully. (Presented in order of difficulty.)

Monographs

\begin{tabular}{ll}
\hline & Word \\
cV & $\begin{array}{l}\text { day } \\
\text { cow }\end{array}$ \\
cve & man \\
cvcc & game \\
& list
\end{tabular}

Digraphs

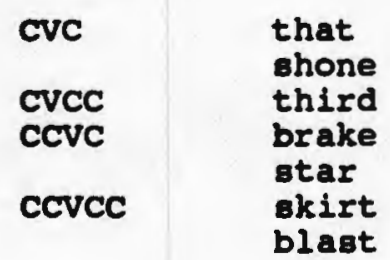

\section{Answer}

aday

owcay

anmay

emegay

18tiay atthay
oneshay
irdthay
rakebay
tarsay
kirtsay
lastbay 
APPENDIX G

SINGLE SYLLABLE MEMORY TEST

Instructions: You are going to hear me bay some sounds through your headphones. They are the kinds of sounds we use when we talk. Right after you hear what I say, you will hear a beep. Then you start reading these numbers (point) outloud as quickly as you can. Read across the page. At the next beep, tell me what you heard me say through the headphones. Let's do some for practice first.

Present the first practice item with a 5-8econd interval.

Present the second practice item with a 10-second interval.

Practice: (1) tae (2) oup

(Presented in the order listed below.)

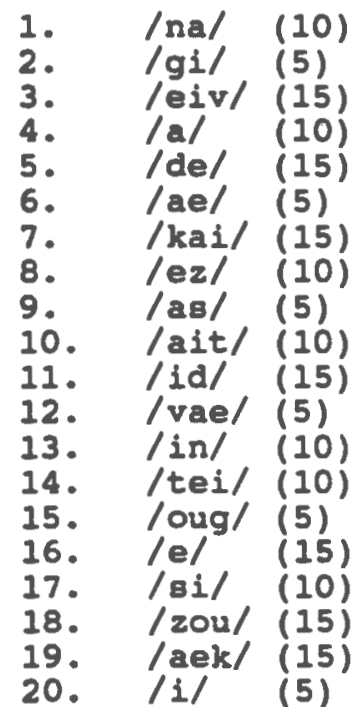




\section{APPENDIX H}

\section{FAMILIAR WORD SPAN MEMORY TEST}

Instructions: This is a memory test. I'm going to play a tape that has lists of words. After each list is finished I want you to repeat the words back as best as you can in the order that you heard them. Let's try practicing some together. (Present at one second intervals.)

Practice:
(1) stop
home light
(2) stove jump help
blue

(Correct wrong responses on practice trials only. Also, if the child pauses as if he/she is not finished and has already recalled three or four items, wait five seconds and ask, "Do you remember any other words from that list?")

List

$\begin{array}{llllll}\text { 1) cat } & \text { fly } & \text { score } & \text { meat } & \text { scale } \\ \text { 2) } & \text { roar } & \text { wheat } & \text { fat } & \text { tail } & \text { sky } \\ \text { 3) } & \text { tie } & \text { hat } & \text { nail } & \text { floor } & \text { oheet } \\ \text { 4) mail } & \text { pie } & \text { store } & \text { cap } & \text { feet } \\ \text { 5) treat } & \text { door } & \text { eye } & \text { gail } & \text { map } \\ \text { 6) bell } & \text { state } & \text { knee } & \text { pain } & \text { chair } \\ \text { 7) } & \text { bee } & \text { cell } & \text { train } & \text { air } & \text { plate } \\ \text { 8) } & \text { gate } & \text { brain } & \text { pair } & \text { tea } & \text { well } \\ \text { 9) } \text { bear } & \text { key } & \text { weight } & \text { shell } & \text { chain } \\ \text { 10) rain } & \text { hair } & \text { spell } & \text { fate } & \text { tree }\end{array}$




\section{APPENDIX I \\ NONSENSE WORD SPAN MEMORY TEST}

Instructions: This is a memory test. I'm going to play a tape that has lists of words -- words that aren't real, for example, pog.

After each list is finished I want you to repeat the words back as best as you can in the order that you hear them. Let's try practicing some together. (Present at one second intervals.)

Practice: (1) nat tiff ib

(2) mell jox leck hap

(Correct wrong responses on practice trials only. Also, if child pauses as if he/she is not finished and has already recalled three items, wait five seconds and ask, "Do you remember any other words from that ist?")

List

1) lat slee flim geat

2) joar wheam fut sko

3) $\mathrm{ni}$ quat floun sheeg

4) paim stas bap feep

5) doot ah paik mab

6) gell stame skow nain

7) tay peli treek plid

8) gade braip gow lell

9) meeb filt shill whib

10) jate spull ter skay 
APPENDIX J

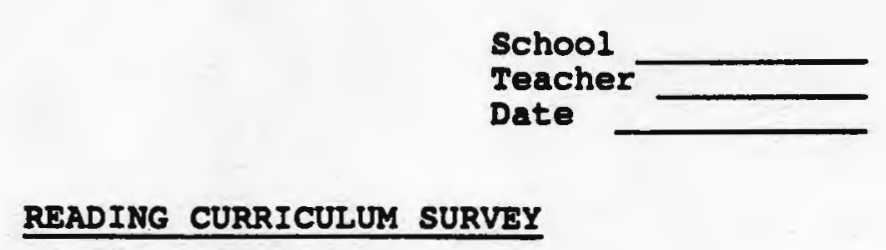

The questions below are intended to assess which reading method you rely on most in your classroom. This information will remain confidential. This feedback will be informative as to whether children in various classes are being taught according to similar or different reading instruction methods.

Thank you again for your cooperation and assistance. After you complete this survey, please return it to me in person or in the enclosed stamped, self-addressed envelope.

$\begin{array}{ll}\text { Rey to Numbers } & 1=\text { minimally: never or less than } 1 \text { on } \\ \text { Scale: } & \text { time per month } \\ 2 & =\text { periodically: two or three times } \\ 3 & =\text { per month } \\ 4 & =\text { reguently: once or twice per week } \\ & \text { four times per week } \\ 5 & =\text { always: daily }\end{array}$

1. Do you use a basal series? yes no If so, which one?

2. Do you teach phonics as a separate unit of study? 1 2 3 4 5

comments:

3. If you teach phonics, do you provide additional reading material that enables the etudent to practice the phonics lessons within context?

1

2

3

4

5

Comments: 
4. Do you emphasize phonics in your other daily curriculum, when appropriate?
1
2
3
4
5

Comments:

5. Do you use children's literature/tradebooks to supplement reading lessons and the basal reader?
1
2
3
4
5

Comments:

6. During this year have you used the Language Experience Approach (1.e., "Today's News" or other stories related by students)?

1

2

3

4

5

Comments:

7. Do you use Process Writing (e.g., emphasize elements of story composition)?
1
2
3
4
5

comments:

8. Do you use Big Books (e.g., classics)?
1
2
3
4
5

Comments:

9. Do children in your class write individual or class books?
1
2
3
4
5

Comments:

10. Do children in your class write in journals?
1
2
3
4

Comments : 
11. Do you use thematic units to integrate content areas with language arts (reading, writing, speaking, listening, math/problem-solving)?

1

2

3

4

5

Comments:

12. Which reading method(s) do you personally prefer?

THANK YOU! 


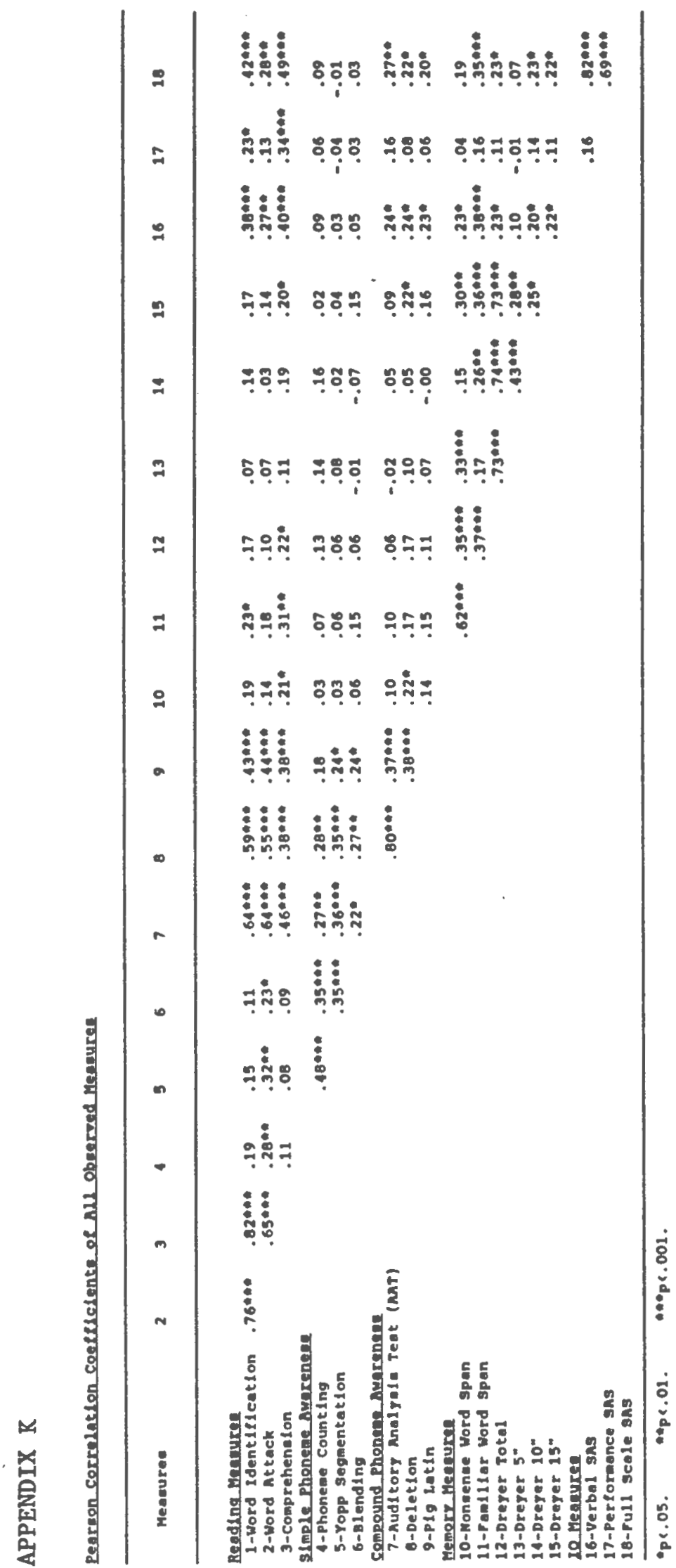


APPENDIX L

Beta Values for Model No. 1

\begin{tabular}{lccccc}
\hline & IQ & WM & CPA & SPA & Reading \\
\cline { 2 - 5 } IB & .00 & .00 & .81 & .27 & .66 \\
WM & & & .49 & .19 & .38 \\
CPA & & & & .00 & .25 \\
SPA & & & & & .23 \\
\hline
\end{tabular}




\section{BIBLIOGRAPHY}

Adams, M. J. (1990). Beginning to read. Cambridge, MA: MIT Press.

Alegria, J., Pignot, E., \& Morais, J. Phonetic analysis of speech and memory codes in beginning readers. Memory and Cognition, 10, 451-456.

Backman, J. (1983). The role of psycholinguigtic skills in reading acquilition: A look at early readers. Reading Research Quarterly, 18, 466-479.

Baddeley, A. (1986). Norking memory. Oxford: Clarendon Press.

Ball, E., \& Blachman, B. (1988). Phoneme segmentation training: Effect on reading readiness. Annals of Dyslexia, 38, 208-225.

Blachman, B. (1983). Are we assessing the linguistic factors critical in early reading? Annals of Dyslexia, 33, 91-109.

Bradley, I., Bryant, P. (1983). Categorizing sounds and learning to read: A causal connection. Nature, 301, 419-421.

Brady, S. (1986). Short-term memory, phonological processes and reading ability. Annals of Dyslexia, 36, 138-153.

Brady, S. (1988, November). Is there a unitary phonological deficit? Paper presented at the meeting of the Orton Dyslexia Society, Tampa, Florida. To appear in S. Brady \& D. Shankweiler (Eds.). Phonological processes in literacy. Hillsdale, NJ: Erlbaum.

Brady, S., Mann, V., \& Schmidt, R. (1987). Errors in short-term memory for good and poor readers. Memory and Cognition, 15, 444-453.

Brady, S., Shankweiler, D., Mann, v. (1983). Speech perception and memory coding in relation to reading ability. Journal of Experimental Child Psychology, 35, 345-367.

Calfee, R., Iindamood, P., Iindamood, C. (1973). Acoustic-phonetic skills and reading - kindergarten through twelfth grade. Journal of Educational Paychology, 64, 293-298.

Cohen, R., Netley, C. (1981). Short-term memory deficits in reading disabled children, in the absence of opportunity for rehearsal itrategies. Intelligence, 5, 69-76.

Conners, F., \& Olson, R. (in press). Reading comprehension in dyslexic and normal readers: A component-skills analysis. In D. A. Balota, G. B. Flores d'Arcaib, \& K. Rayner (EdB.), Comprehension processes In reading. Hilladale, NJ: Erlbaum.

Dreyer, I. (1989). The relationship of children's phonological memory to decoding and reading ability. Unpublished doctoral dissertation, Columbia University.

Fox, R., Routh, D. (1976). Phonemic analysis and gynthesis as wordattack skilis. Journal of Educational Psychology, 68, 70-74. 
Fox, B., E Routh, D. (1980). Phonemic analygis and severe reading disability in children. Journal of Psycholinguistic Research, 9 , 115-119.

Fox, B., Routh, D. (1983). Reading disability, phonemic analysis and dysphonetic speliing: A follow-up study. Journal of Clinical Child Psychology, 12, 28-32.

Fox, B., Routh, D. (1984a). MM . . Is a little bit of may: Phonemes, reading, and spelling. Advances in Learning and Behavioral Disabilities, 3 , 95-124.

Fox, B., Routh, D. (1984b). Phonemic analysis and synthesis as word attack skilis: Revisited. Journal of Educational Paychology, 76, 1059-1064.

Gathercole, S., Baddeley, A. (1989). Evaluation of the role of phonological STM in the development of vocabulary in children: A longitudinal study. Journal of Memory and Language, 28, 200-213.

Gathercole, S., willis, C., \& Baddeley, A. (1990). Differentiating phonological memory and awareness of rhyme: Reading and vocabulary development in children. Manuscript submitted for publication.

Goldstein, D. (1976). Cognitive-1inguistic functioning and learning to read in preschoolers. Journal of Educational Prychology, 68, 680-688.

Katz, R., Shankweller, D., IL Iberman, I. (1981). Memory for item order and phonetic recoding in the beginning reader. Journal of Experimental Child Peychology, 32, 474-484.

Liberman, I. (1973). Segmentation of the spoken word and reading acquisition. Bullet in of the orton Society, 23, 65-77.

Liberman, I., Shankweiler, D., Fischer, F., C Carter, B. (1974). Explicit syllable and phoneme segmentation in the young child. Journal of Experimental Child Psychology, 18, 201-212.

Lundberg, I., Frost, J., Petersen, O. (1988). Effects of an extensive program for stimulating phonological awareness in preschool children. Reading Research quarterly, 23, 263-284.

Mann, v. (1984). Longitudinal prediction and prevention of early reading difficulty. Annals of Dyslexia, 34, 117-136.

Mann, V., Cowin, E., \& Schoenheimer, J. (1989). Phonological processing, language comprehension, and reading ability. Journal of Learning Digabilities, 22, 76-89.

Mann, V., Liberman, I. (1984). Phonological awareness and verbal ahort-term memory. Journal of Learning Disabilities, 17, 592-599.

Morais, J. (1987). Phonetic awareness and reading acquisition. Peychological Research, 49, 147-152.

Olson, R., Wise, B., Conners, F., Rack, J., \& Fulker, D. (1989). specific deficits in component reading and language skills: Genetic and Environmental Influences. Journal of Learning Disabilities, 22, 339-348. 
Pennington, B., Van Orden, G., Kirson, D., Haith, M. (in press). What is the causal relation between verbal STM problems and dyolexia? In S. Brady D. Shankweller (Eds.), phonological processes in literacy. Hillsdale, NJ: Erlbaum.

Perfett1, C., Beck, I., Bell, I., Hughes, C. (1987). Phonemic knowledge and learning to read are reciprocal: A longitudinal study of first grade children. Merill-Palmer quarterly, 33, 283319 .

Pratt, A., Brady, S. (1988). Relation of phonological awareness to reading disability in children and adults. Journal of Educational Prychology, 80, 319-323.

Rapala, M., Brady, S. (In press). Reading ability and short-term memory: The role of phonetic processing. Reading and Writing.

Rosner, J., Simon, D. (1971). The auditory analysis test: An initial report. Journal of Learning Disabilities, 4, 384-392.

Shankweiler, D., Liberman, I., Mark, L., Fowler, C., Eischer, F. (1979). The speech code and learning to read. Journal of Experimental Paychology: Human Learning and Memory, 5, 531-545.

Share, D., Jorm, A., Maclean, R., Matthews, R. (1984). Sources of individual differences in reading acquistion. Journal of Educational Prychology, 76, 1309-1324.

Siegel, I., \& Linder, B. (1984). Short-term memory processes in children with reading and arithmetic learning disabilities. Developmental Peychology, 20, 200-207.

Snowling, M. (1981). Phonemic deficits in developmental dyslexia. Psychological Research, 43, 219-234.

Spring, C., capps, c. (1974). Encoding speed, rehearsal, and probed recall of dyslexic boys. Journal of Educational Psychology, 66, 780-786.

Stanovich, R. (1982). Individual differences in the cognitive processes of reading: Text-level processes. Journal of Learning Disabilitieg, 15, 549-554.

Stanovich, $K$. (1986). Explaining the variance in reading ability in terms of psychological processes: What have we learned? Annals of Dyslexia, 35, 67-96.

Stanovich, K. (in press). Discrepancy definitions of reading disability: Has intelligence led us astray? Reading Research guarterly.

Stanovich, K., Cunningham, A., Cramer, B. (1984). Assessing phonological awareness in kindergarten children: Issues of task comparability. Journal of Experimental Child Paychology, 38, 175190.

stanovich, R., Cunningham, A., Feeman, D. (1984). Intelligence, cognitive skills, and early reading progress. Reading Research Quarterly, 14, 278-303. 
Stanovich, R., West, R., \& Cunningham, A. (in press). Beyond phonological processes: Print exposure and orthographic processing. In S. Brady \& D. Shankweiler (Eds.), Phonological processes in literacy. Hillsdale, NJ: Erlbaum.

Thorndike, R., Hagen, E., \& Sattler, J. (1986). Stanford-Binet intelligence scale: Fourth edition technical manual. Chicago, IL: Riverside Publishing.

Torgesen, J. (1978-79). Performance of reading disabled children on serial memory tasks: A selective review of recent research. Reading Research quarterly, 14, 57-87.

Torgesen, J. (1985). Memory processes in reading disabled children. Journal of Learning Disabilities, 18, 350-357.

Torgesen, J. (1989). Cognitive and behavioral characteriatics of children with learning disabilities: Concluding comments. Journal of Learning Disabilities, 22, 166-168.

Torgesen, J., \& Houck, D. (1980). Processing deficiencies in learning disabled children who perform poorly on the digit span test. Journal of Educational Psychology, 72, 141-160.

Turner, M., \& Engle, R. (1989). Is working memory capacity task dependent? Journal of Memory and Language, 28, 127-154.

Vellutino, F. (1987). Dyslexia. Scientific American, 256, 34-41.

Vellutino, F., \& Scanlon, D. (1987). Phonological coding, phonological awareness, and reading ability: Evidence from a longitudinal and experimental study. Merrill-Palmer Ouarterly, 33, 321-363.

Vellutino, F., Smith, H., Steger, J., \& Kaman, M. (1975). Reading disability: Age differences and the perceptual-deficit hypothesis. Child Development, 46, 487-493.

Wagner, R. (1986). Phonological processing abilities and reading: Implications for disabled readers. Journal of Learning Disabilities, 19, 623-630.

Wagner, R. (1988). Causal relations between the development of phonological processing abilities and the acquisition of reading skills: A meta-analysis. Merrill-Palmer quarterly, 34, 261-279.

Wagner, R., Balthazor, M., Hurley, S., Morgan, S., Rashotte, C., Shaner, R., Simmons, K., stage, S. (1987). The nature of prereaders' phonological processing abilities. Cognitive Development, 2, 355373.

Wagner, R., \& Torgesen, J. (1987). The nature of phonological processing and its causal role in the acquisition of reading akills. Paychological Bulletin, 101, 192-212.

Williams, J. (1980). Teaching decoding with an emphasis on phoneme analysis and phoneme blending. Journal of Educational Psychology, 72, 1-15.

Woodcock, R. (1987). Woodcock reading mastery tests-Revised. Circle Pines, MN: American Guidance Service. 
Yopp, H. (1988). The validity and reliability of phonemic awareness tests. Reading Research Quarterly, 23, 159-177. 